\title{
GROWTH AND DIFFERENTIATION IN APRICOT TREES
}

H. S. REED

University of California Publications in Agricultural Sciences

Vol. 5, No. 1, pp. 1-55, 18 figures in text

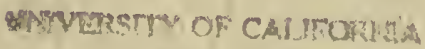

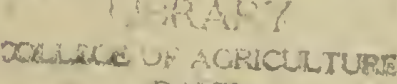

DAYIg

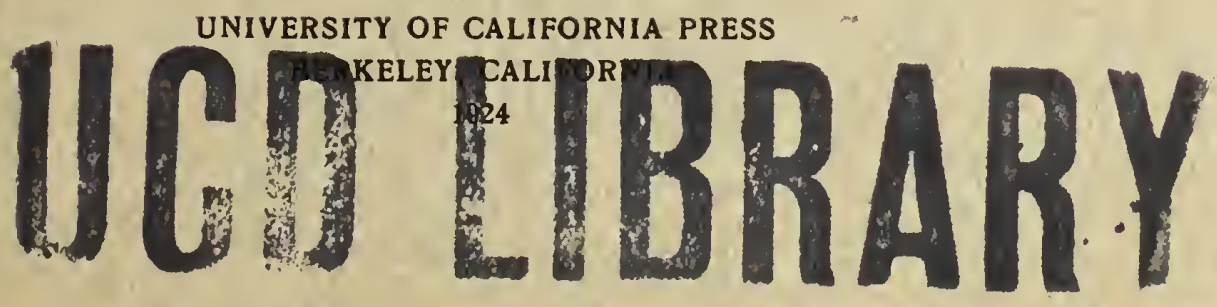




\section{UNIVERSITY OF CALIFORNIA PUBLICATIONS}

Note.-The University of California Publications are offered in exchange for the publ1cations of learned societies and institutions, universities and libraries. Complete Hsts of all the publications of the University will be sent upon request. For sample copies, lists of publications and other information, address the MANAGER OF THE UNIVERSITY PRESS, BERKELEY, CAIIFORNIA, U. S. A. All matter sent in exchange should be addressed to THE EXCHANGE DEPARTMENT, UNIVERSITY LIBRARY, BERKELEY, CAIIFORNIA, U. S. A.

AGRICULTURAL SCIENCES.-C. B. Lipman, H. S. Reed, R. E. Clausen, Editors. Price per volume, \$5. Volume 1 (587 pages), 3 (509 pages), and 4 (450 pages) completed. Volumes 2 and 5 in progress.

Vol. 2. 1. Studies in Juglans. I. Study of a New Form of Juglans californica Watson, by Ernest B. Babcock. Pp. 1-46, plates 1-12. December, 1913

$\$ 0.60$

2. Studies in Juglans. II. Further Observations on a New Variety of Juglans californica Watson and on Certain Supposed Walnut-Oak Hybrids, by Ernest B. Babcock. Pp. 47-70, plates 13-19. October, 1914

3. Studies in Juglans. III. (1) Further Evidence that the Oak-like Wainut Originates by Mutation; (2) A Parallel Mutation in Juglans hindsii (Jepson) Sargent, by Ernest B. Babcock. Pp. 71-80, plates 20-21. September, 1916

4. Mutation in Matthiola, by Howard B. Frost. Pp. 81-190, plates 22-35. November, 1919

5. Interspecific Hybrids in Crepis. I. Crepis Capillaris (L.) Wallr. $X$ C. Tectorum I., by Ernest B. Babcock and Julius L. Collins. Pp. 191-204, plates 36-38. October, 1920

6. Inbreeding and Crossbreeding in Crepis Capillaris (I.) Wall., by Julius I. Collins. Pp. 205-216, plates 39-41. November, 1920

7. Inheritance of Some Morphological Characters in Crepis capillaris, by Venkata Rau. Pp. 217-242, plates 42-43, 3 figures in text. June, $1923 . .$.

8. Microsporogenesis of Ginkgo biloba $\mathrm{L}$. with especial reference to the Distribution of the Plastids and to Cell Wall Formation, by Margaret Campbell Mann. Pp. 243-248, plate 52. September, 1924

Vol. 3. 1. New Grasses for California. I. Phalaris stenoptera Hack., by P. B. Kennedy. Pp. 1-24, plates 1-8. July, 1917

2. Optimum Moisture Conditions for Young Lemon Trees on a Loam Soll, by L. W. Fowler and C. B. Lipman. Pp. 25-36, plates 9-11. September, 1917.

3. Some Abnormal Water Relations in Citrus Trees of the Arid Southwest and Their Possible Significance, by Robert W. Hodgson. Pp. 37-54, plate 12. September, 1917

4. A New Dendrometer, by Donald Bruce. Pp. 55-61. November, 1917 ...........

5. Toric and Antagonistic Effects of Salts on Wine Yeast (Saccharomyces ellipsoideus), by S. K. Mitra. Pp. 63-102. November, 1917

6. Changes in the Chemical Composition of Grapes during Ripening, by $\mathbf{F}$. T. Bioletti, W. V. Cruess, and H. Davi. Pp. 103-130. March, 1918

7. A New Method of Extracting the Soll Solution (a Preliminary Communication); by Charles B. Lipman. Pp. 131-134. March, 1918

8. The Chemical Composition of the Plant as Further Proof of the Close Relar tion between Antagonism and Cell Permeability, by Dean David Waynick. Pp. 132-242, plates 13-24. June, 1918.

9. Variability in Soils and Its Significance to Past and Future Soil InvestIgations. I. A Statistical Study of Nitrification in Soil, by Dean David Waynick. Pp. 243-270, 2 text figures. June, 1918

10. Does $\mathrm{CaCo}_{3}$ or $\mathrm{CaSo}_{4}$ Treatment Affect the Solubility of the Soil's Constituents?, by C. B. Lipman and W. F. Gericke. Pp. 271-282. June, 1918.

11. An Investigation of the Abnormal Shedding of Young Fruits of the Washington Navel Orange, by J. Eliot Coit and Robert W. Hodgson. Pp. 283-368, plates 25-42, 9 text figures. April, 1919

12. Are Soils Mapped under a Given Type Name by the Bureau of Solls Method Closely Similar to One Another?, by Robert Larimore Pendleton. Pp. 369-498, plates 43-74, 33 text figures. June, 1919

Vol. 4. 1. The Fermentation Organisms of Callornia Grapes, by W. V. Cruess. Pp. $1-66$, plates $1-2,15$ text figures. December, 1918

2. Tests of Chemical Means for the Control of Weeds. Report of Progress, by George P. Gray. Pp. 67-97, 11 text figures

3. On the Existence of a Growth-Inhibiting Substance in the Chinese Iremon, by H. S. Reed and F. F. Halma. Pp. 99-112, plates 3-6. February, 1919. 
GROWTH AND DIFFERENTIATION

IN APRICOT TREES

BY

H. S. REED 
Uyiversity of California Publications in Agricultural Sciences Volume 5, No. 1, pp. 1-55, 18 figures in text Issued September 30, 1921 


\title{
GROWTH AND DIFFERENTIATION IN APRICOT TREES*
}

\author{
BY
}

H. S. REED

\section{INTRODUCTION}

The 'habit of growth' of a species or variety is a character to which reference is often made in botanical discussions. The pattern of an organism is the result of a proeess of growth and differentiation which is largely an expression of faetors inherent in that organism. Growth produces not only an inerease in size; it is aeeompanied as well by a complex differentiation of the organism. Nothing eould be more important than an investigation of these processes in order to diseover the fundamental prineiples which govern them. Those who are interested in the broader problems of biology will be coneerned with the laws of growth, while those who are interested in the art of horticulture may gather from sueh a study something that is fundamental in fruit. production.

There are two well reegnized methods of attaeking the problem of growth: the experimental and the observational. So far as the dynamies of growth are coneerned, the experimental method of study, dealing largely with faetors whieh eontrol proeesses, may be expected to yield useful information. But when dealing with growth in relation to differentiation, and with the problem of correlation of different members of an organism, the observational method is of great importanee, and it is this method that was employed in the present investigation.

The writer has shown in earlier papers that the growth of an organism, or organ, proeeeds in a definite, orderly fashion, and that it is possible to express the rate of growth by a mathematical equation. This contributes nothing, of eourse, to our knowledge of the eauses of growth, but does emphasize the fact that the form and the funetion of organisms, though variable, nevertheless are not outside the realm of exact seienee. With respeet to apricot branehes, it is known that their growth in length conforms to an equation in which the size is shown to be a definite funetion of the time.

* Paper No. 112, University of California, Graduate School of Tropical Agriculture and Citrus Esperiment Station, Riverside, California. 
In the present paper variability and differentiation in apricot branches will be discussed at length. In respect to length of main axis and percentage of buds which overcame dormancy in the first season, variability was not excessive. In respect to other characters, however, variability was very great. Amount of growth, for example, is apparently largely determined by fortuity of position, because of rarying reaction to heat and light. Diverse types of development are manifested by orthotropic and plagiotropic branches. A large part of the material and energy at the disposal of the branch is devoted to forming structures which, though subsidiary, exceed in size the main axis of the branch. It will be important, therefore, to investigate the quantitative relationships between branches and their members.

The greatest growth of laterals is produced on the most vigorous branches. The unity of the organism is demonstrated by the close relationship between the vigor of the branch and the vigor of the laterals produced on it. Speaking in chemical terms, we might say that variations in the quantity of growth-promoting substances or of tissue-forming materials are uniformly distributed throughout a bramclr. Although the terminal portion of a branch exerts a dominant influence over the development of the subterminal portions, the factors which tend to promote growth in one region tend also to promote growth in another.

The most casual observer cannot help noticing, in figure 1 , the three distinct groups of laterals on the branches. Between adjacent groups there are many buds whose dormancy was not broken during the first growing season. The quantitative characters of these groups have been of great interest in the study of the pattern of the apricot branches, because they indicate a certain definite distribution of mass along the axis of the branch.

A former study of growth in young pear trees ${ }^{9}$ showed that the size of a shoot is a function of its position on the motler shoot. The present study shows that the shape and size of these groups of laterals is a function of their position on the main axis; in other words, that their specific method of development is a quantitative character. This relationship seems to be highly important and to support the idea that the growth process (in its simplest form) brings about a definite distribution of matter in space which takes the form of a characteristic pattcrn. The position and size of the haterals on the branches must be regarded as the result of a process of differentiation which as yet has becn but little studied with referenec to its quantitative characters. 
Herbert Spencer ${ }^{12}$ has stated the problem suceinetly.

The morphological differentiation which thus goes hand in hand with morphological integration is clearly what the perpetually-complicating conditions would lead us to anticipate. Every addition of a new unit to an aggregate of such units must affect the circumstances of the other units in all varieties of ways and degrees, according to their relative positions, must alter the distribution of mechanical strains throughout the mass, must modify the process of nutrition, must affect the relations of neighboring parts to surrounding diffused actions; that is, must initiate a changed incidence of forces tending ever to produce changed structural arrangements.

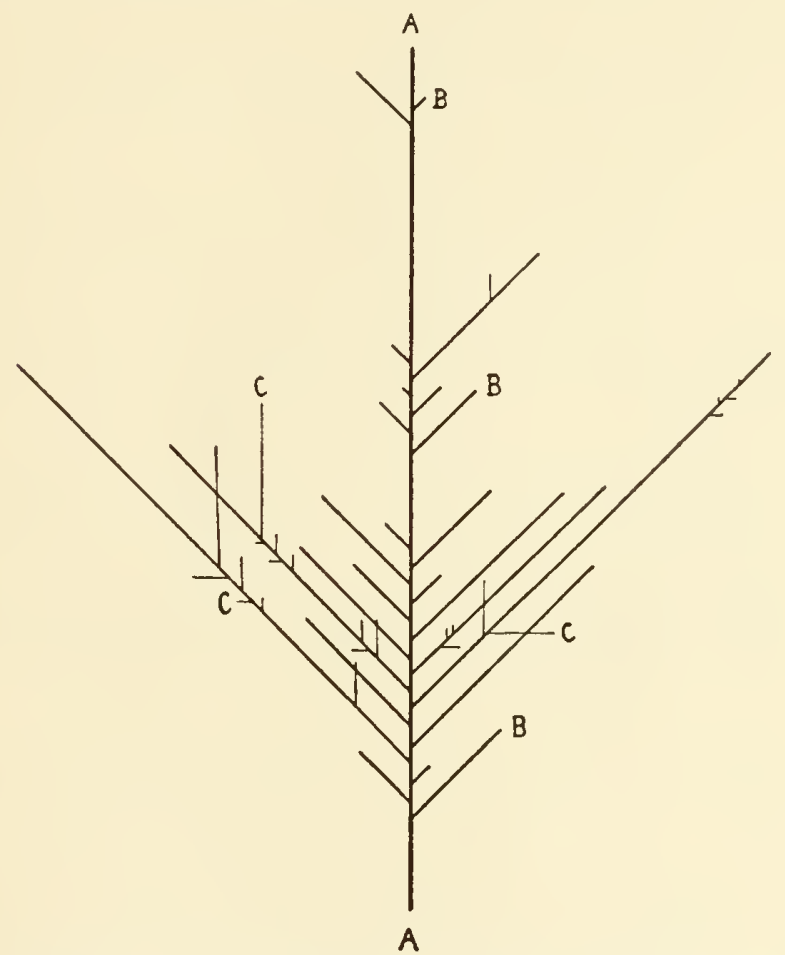

Fig. 1. Diagram of a young apricot branch showing the type of material used in the study. A A, braneh axis; B, primary lateral; C, secondary lateral.

The data to be presented afford strong evidence that the number of laterals per branch is largely determined by factors which impose a condition of dormancy upon the buds of most of the nodes. The greater number of branches have relatively few laterals. This condition is of obvious interest to horticulturists, who find it necessary to employ various means of promoting the formation of laterals. So far as possible, the factors which influence the production of laterals have been studied, and the need for further investigation indicated. 
The production of flower-buds on the branches is another question of biological interest. The number of blossoms on a branch is necessarily dependent upon the number of laterals it produces, but long laterals show no tendency to be more prolific in blossoms than their shorter neighbors. One important exception to this relation was found in the case of primary laterals, where there appeared to be a distinct group of relatively long laterals possessing from 50 to 110 nodes, in which the inajority produced less than five blossoms each. This group might be regarded as being predominantly vegetative in activity, while the other laterals were both vegetative and reproductive in function. There is a notable difference in the number of blossoms per lateral of different groups, which is probably caused in large measure by differences in age of the several groups.

If we assume that there is some sort of an equilibrium in the tree between forces producing vegetative and reproductive growth, we may understand better the various correlations between blossoms and other characters which are to be studied in the following pages. Speaking broadly, we may say that each lateral appeared to produce about the same number of blossoms as its neighbors of approximately the saine age, and that the number of blossoms on a lateral was more or less independent of the number of nodes which the lateral possessed. In other words, it may be a matter of indifference to the fruit grower whether the branches have long laterals or short laterals so far as the capacity of the trees to produce 'fruit buds' is concerned.

In the apricot trees studied the equilibrium between forces influencing vegetative and reproductive growth varied, apparently, only between limits. The variability in the number of blossoms per branch is large and may possibly indicate that the equilibrium between forees is relatively unstable. The average number of blossoms per branch was 360 , but the actual numbers ranged from 50 to 1200. This wide variability may have resulted from the fact that we were dealing in this case solely with young branches produced in the preceding season. The data give some evidence on the opposition of growth processes to fruit-bud formation. It was found that, while the distal region of the branch was actively growing, the physiological functions of that region were opposed to the formation of energy centers which produce fruitbuds. In the proximal region, where vegetative growth had largely ceased before the end of the season, the formation of fruit buds was not opposed by other functions. 


\section{DESCRIPTION OF' THE MATERIAL}

The data for the present study were obtained from four-year-old apricot (Prunus armeniaca) trees of the horticultural variety known as Royal. The trees stand in an orchard at the Citrus Experiment Station, Riverside, California. Measurements were taken of 79 branches which had grown in the preceding year. The branches were selected from 36 different trees scattered over the orchard in such a way as to give a fairly random distribution. Figure 1 shows in a diagrammatic way the morphology of a typical branch selected from the population studier.

There are advantages and disadvantages in working with material from a clonal variety which, for many ycars, has been propagated by budding. A budded tree has something of the nature of a dual organism, since it is growing upon the root of a seedling tree. The clonal quantitative characteristies may be somewhat modified by the vigor of the stock upon which the variety is propagated, though it is doubtful whether a group of trees like these would have as great variability as a similar number of unbudded seedling trees, The Royal apricot probably originated in France. "This valuable sort was raised in the Royal garden of the Luxembourg, whence a plant was sent to the [Roval Horticultural] society [of London] by M. Hervy, the Director. It fruited in the Garden in 1828 and was then figured in the Pomological magazine. ${ }_{14}$

In the discussion, the following terms will be used: 'branches' are the 79 shoots which make up the population under study; 'mother shoots' are the year-old limbs on which the population grew ; 'primary laterals' are the shoots which grew from certain nodes of the branches; 'secondary laterals' are shoots which grew on the primary laterals.

The mother shoots were pruned by the amputation of about threefourths of their length in the early spring of 1920 . The 79 branches upon which this study is based grew during the following season from buds situated a short distance back of the points at which the mother shoots had been amputated. The favorable position of the branches, as well as the severe pruning of the mother shoots, unquestionably had much to do with this vigorous growth.

The primary and secondary laterals were developed as the branch grew and reached a total length which averaged 7 to 8 times the length of the main axis on which they were borne (fig. 1). 
During the growing season measurements were made each week to determine the length of the branches. The length of the primary and secondary latcrals was not determined during the growing season. It the end of the growing season an extensive series of measurements was made covering the length and circumference of the branches, number of laterals, number of dormant buds, and number of blossoms. These measurements of the shoot systems with their adherent laterals serve as a basis for the present study.

The vegetative shoots of the apricot tree constitute very favorable material for the study of growth relationships. Previous papers from this laboratory ${ }^{6,7,8}$ have presented some of the salient features in the growth of shoots like those here studied. Except for the vigor and rapidity of their growth these shoots differed in no essential from those of other fruit trees which have been under observation.

In the early part of the growing season the apricot shoots grow very rapidly, making about half their season's growth in the first seven to nine weeks. The rate of growth usually attained its first maximum in the fifth or sixth week of the season, then gradually declined with more or less irregularity to about the fourteentl week; it reached a second maximum about the seventeenth week and fell to its final minimum from the twenty-fifth to the twenty-eighth week. This tendency to eyclic growth is eharacteristic of many trees and is well illustrated by the growth of the apricot shoots.

The growing season for apricot shoots in the locality mentioned usually begins in March and extends to some time late in autumn. It is therefore necessary to make measurements of the elongation over a total period of eight or nine months.

Results of an earlier investigation ${ }^{6}$ showed that there were threc eycles in the seasonal growth of a sample of vegetative shoots and that the growth in each cycle could be quantitatively expressed by the equation

$$
\log \frac{x}{a-x}=K\left(t-t_{1}\right)
$$

In this case $x$ is the length of the shoots at time $t ; a$ is their final length; $t_{1}$ is the time at which the shoots have been made one-half of their final length $a$; and $K$ is a constant. This equation has been found to express the growth of both plants and animals, and is useful in analyzing the growth process. The rate of growth of apricot shoots is definitely related to the final length $a$, with distinct quantitative differences between shoots of various length through the entire season. ${ }^{7}$ 
Pruning the trees severely in the dormant period had a marked influence upon the sap concentration and the rate of growth of vegetative shoots in the following season. Sap concentration on rapidly growing shoots was usually much less than on slowly growing shoots, and showed a descending gradient from the apex toward the base of the shoots. ${ }^{8}$

The final measurements of the branches and their parts were taken with the assistance of Mr. F. F. Halma and Dr. A. R. C. Haas in the spring of 1921 just before the beginning of growth. Not only length and number of buds were recorded for each branch and lateral, but the position of each lateral on the sloot which bore it was recorded. Table 1 presents the data in a condensed form.*

\footnotetext{
* The writer realizes the advisability of publishing the original data, but, for reasons of economy, is unable to do so. The original figures have been preserved and may be consulted by anyone who wishes to use them.
} 
TABLE 1

Sumarary of Data on Apricot Branches

\begin{tabular}{|c|c|c|c|c|c|c|c|c|c|c|}
\hline $\begin{array}{c}\text { Branch } \\
\text { No. }\end{array}$ & $\begin{array}{c}\text { Angle } \\
\text { from } \\
\text { perpen- } \\
\text { dicular } \\
\text { (dgrs.) } \\
\end{array}$ & $\begin{array}{c}\text { Loca- } \\
\text { tion }\end{array}$ & $\begin{array}{c}\text { Length } \\
\text { (cm.) }\end{array}$ & $\begin{array}{l}\text { Total } \\
\text { no. of } \\
\text { nodes }\end{array}$ & $\begin{array}{c}\text { No. } \\
\text { dor- } \\
\text { mant } \\
\text { nodes }\end{array}$ & $\begin{array}{l}\text { No. } \\
\text { pri- } \\
\text { mary } \\
\text { later- } \\
\text { als }\end{array}$ & $\begin{array}{l}\text { No. } \\
\text { second- } \\
\text { ary } \\
\text { later- } \\
\text { als }\end{array}$ & $\begin{array}{l}\text { Length } \\
\text { of all } \\
\text { pri- } \\
\text { mary } \\
\text { later- } \\
\text { als } \\
(\mathrm{cm} .) \\
\end{array}$ & $\begin{array}{l}\text { Length } \\
\text { of all } \\
\text { second- } \\
\text { ary } \\
\text { later- } \\
\text { als } \\
\text { (cm.) }\end{array}$ & $\begin{array}{l}\text { No. } \\
\text { of } \\
\text { blos- } \\
\text { soms }\end{array}$ \\
\hline 1 & 30 & $\mathrm{NE}$ & $2+6$ & 148 & 116 & 32 & 21 & 1029 & 198 & 320 \\
\hline 2 & 50 & $\mathrm{~S}$ & 257 & 130 & 101 & 29 & 59 & 1473 & 1128 & 1066 \\
\hline 3 & 50 & $S E$ & 241 & 145 & 116 & 29 & 13 & 1133 & 111 & 495 \\
\hline 4 & 90 & $\mathrm{SE}$ & 235 & 138 & 103 & 35 & 20 & 1057 & 269 & 383 \\
\hline 5 & 45 & $\mathrm{~N}$ & 237 & 126 & 82 & 44 & 62 & 2021 & 1124 & 714 \\
\hline 6 & 80 & SE & 263 & 153 & 120 & 33 & 79 & 2016 & 1304 & 347 \\
\hline 7 & 50 & $W$ & 195 & 114 & 86 & 28 & 41 & 1164 & 686 & 238 \\
\hline $\mathrm{s}$ & 30 & $N W$ & 230 & 121 & 57 & 64 & 136 & 3078 & 1852 & 503 \\
\hline 9 & 90 & $\mathrm{SE}$ & 224 & 128 & 110 & 18 & 19 & 475 & 177 & 249 \\
\hline 10 & 90 & $s$ & 233 & 125 & S4 & 41 & 71 & 2011 & 1307 & 534 \\
\hline 11 & 60 & $\mathrm{NE}$ & 267 & 136 & 97 & 39 & 77 & 2765 & 1509 & $43 \pi$ \\
\hline 12 & 75 & SW & 220 & 126 & 93 & 33 & 51 & 1626 & 715 & 235 \\
\hline 13 & 90 & $\mathrm{NW}$ & 227 & 137 & 103 & 34 & 12 & 1095 & 108 & 192 \\
\hline 14 & 90 & $s$ & 263 & 134 & 99 & 35 & 109 & 26335 & 1795 & $30 \overline{7}$ \\
\hline 1.5 & 75 & $N$ & 251 & 145 & 110 & 35 & 49 & 1505 & $96 t$ & 231 \\
\hline 16 & 45 & $\mathrm{NE}$ & 267 & 149 & 92 & 57 & 133 & $2 \$ 16$ & 1903 & 753 \\
\hline 17 & 45 & $\mathrm{SE}$ & 289 & 164 & 100 & 64 & 127 & 2765 & 2845 & 293 \\
\hline 18 & 90 & $\mathrm{E}$ & 270 & 154 & 126 & $2 S$ & 60 & 1659 & 775 & 527 \\
\hline 19 & 30 & W & 280 & 178 & 126 & 52 & 103 & $2 s 04$ & 1755 & 391 \\
\hline 20 & 45 & S & 305 & 148 & 92 & 56 & 117 & 3169 & 2157 & 612 \\
\hline 21 & 80 & SW & 231 & 127 & 96 & 31 & 30 & 1677 & 333 & 374 \\
\hline 22 & 60 & $\mathrm{E}$ & 260 & 137 & 98 & 39 & 39 & 1739 & 462 & 302 \\
\hline 23 & 90 & $\mathrm{SE}$ & 223 & 144 & 120 & 21 & 19 & 1005 & 389 & 166 \\
\hline 24 & 75 & $N$ & 152 & 77 & 39 & 38 & 13 & 866 & 93 & 134 \\
\hline 25 & 50 & $S W$ & 223 & 134 & 91 & 43 & $2 t$ & 1248 & 227 & 358 \\
\hline 26 & 0 & SE & 218 & 138 & 78 & 60 & 69 & 1672 & 846 & 547 \\
\hline 27 & 90 & $\mathrm{E}$ & 221 & 113 & 88 & 25 & 4 & 703 & 36 & 115 \\
\hline 28 & 45 & $S W$ & 227 & 124 & 98 & 26 & 18 & 1013 & 173 & 514 \\
\hline 29 & 85 & $\therefore W$ & 260 & 129 & 95 & 34 & 10 & 955 & 173 & 450 \\
\hline 30 & 85 & $S$ & 260 & 134 & 100 & 34 & 25 & $S 60$ & 424 & 530 \\
\hline 31 & 30 & $N$ & 283 & 151 & 105 & 46 & 41 & $160 \mathrm{~s}$ & 536 & 645 \\
\hline 32 & 90 & $\mathrm{~S}$ & 137 & 82 & 64 & 18 & 8 & 338 & 57 & 298 \\
\hline 33 & 85 & $\mathrm{NW}$ & 211 & 110 & 78 & 32 & 49 & 1510 & 683 & 523 \\
\hline 34 & 70 & $S$ & 238 & 129 & 98 & 31 & 22 & 1199 & 206 & 468 \\
\hline 35 & so & Wr & 202 & 111 & 76 & 35 & 19 & 1077 & 163 & 491 \\
\hline 36 & 90 & $\mathrm{SE}$ & 180 & 75 & 48 & 27 & 0 & 760 & 0 & 162 \\
\hline 37 & 50 & $S E$ & 191 & 112 & 96 & 16 & 1 & 371 & 14 & 185 \\
\hline 38 & 90 & SII & 216 & 109 & 78 & 31 & 2 & 716 & 42 & 259 \\
\hline 39 & 90 & IV & 229 & $13 \mathrm{~s}$ & 112 & 26 & 2 & 583 & 13 & 27 \\
\hline 40 & 45 & $S E$ & 253 & 144 & 101 & 43 & 22 & 2004 & 288 & 104 \\
\hline
\end{tabular}


TABLE 1-(Continued)

\begin{tabular}{|c|c|c|c|c|c|c|c|c|c|c|}
\hline $\begin{array}{c}\text { Branch } \\
\text { No. }\end{array}$ & $\begin{array}{c}\text { Angle } \\
\text { from } \\
\text { perpen- } \\
\text { dicular } \\
\text { (dgrs.) }\end{array}$ & $\begin{array}{c}\text { Loca- } \\
\text { tion }\end{array}$ & $\begin{array}{l}\text { Length } \\
(\mathrm{cm} .)\end{array}$ & $\begin{array}{l}\text { Total } \\
\text { no. of } \\
\text { nodes }\end{array}$ & $\begin{array}{l}\text { No. } \\
\text { dor- } \\
\text { mant } \\
\text { nades }\end{array}$ & $\begin{array}{c}\text { No. } \\
\text { pri- } \\
\text { mary } \\
\text { later- } \\
\text { als }\end{array}$ & $\begin{array}{l}\text { No. } \\
\text { second- } \\
\text { ary } \\
\text { later- } \\
\text { als }\end{array}$ & $\begin{array}{l}\text { Length } \\
\text { of all } \\
\text { pri- } \\
\text { mary } \\
\text { later- } \\
\text { als } \\
\text { (cm.) }\end{array}$ & $\begin{array}{l}\text { Length } \\
\text { of all } \\
\text { second- } \\
\text { ary } \\
\text { later- } \\
\text { als } \\
\text { (cm.) }\end{array}$ & $\begin{array}{l}\text { No. } \\
\text { of } \\
\text { blos- } \\
\text { soms }\end{array}$ \\
\hline 41 & 80 & SE & 235 & 141 & 108 & 33 & 13 & 1031 & 144 & 90 \\
\hline 42 & 50 & $\mathrm{~S}$ & 211 & 115 & 74 & 41 & 5 & 888 & 78 & 146 \\
\hline 43 & 90 & $\mathrm{E}$ & 211 & 87 & 67 & 20 & 4 & 377 & 19 & 151 \\
\hline 44 & 80 & $\mathrm{~S}$ & 256 & 144 & 110 & 34 & 12 & 1584 & 222 & 230 \\
\hline 45 & 40 & $\mathrm{SE}$ & 312 & 157 & 103 & 54 & 100 & 2643 & 1576 & 639 \\
\hline 46 & 90 & SW & 218 & 117 & 104 & 13 & 0 & 262 & 0 & 159 \\
\hline 47 & 80 & $\mathrm{E}$ & 225 & 122 & 95 & 27 & 0 & 578 & 0 & 28.5 \\
\hline 48 & 70 & $\mathrm{E}$ & 258 & 135 & 98 & 37 & 31 & 1059 & 484 & 283 \\
\hline 49 & 70 & $S$ & 216 & 130 & 108 & 22 & 11 & 509 & 235 & 108 \\
\hline 50 & 75 & $W$ & 253 & 154 & 123 & 31 & 11 & 846 & 170 & 190 \\
\hline 51 & 45 & $\mathrm{E}$ & 255 & 121 & 86 & 35 & 31 & 1207 & 582 & 451 \\
\hline 52 & 85 & $\mathrm{SE}$ & 263 & 133 & 104 & 29 & 15 & 1098 & 194 & 270 \\
\hline 53 & 90 & W & 230 & 136 & 120 & 16 & 2 & 381 & 21 & 216 \\
\hline 54 & 45 & $\mathrm{NE}$ & 265 & 130 & 82 & 48 & 46 & 2148 & 778 & 899 \\
\hline 55 & 90 & $\mathrm{SE}$ & 249 & 124 & 104 & 20 & 4 & 583 & 66 & 240 \\
\hline 56 & 90 & $\mathrm{SE}$ & 226 & 124 & 102 & 22 & 1 & 510 & 5 & 198 \\
\hline 57 & 90 & $\mathrm{~S}$ & 212 & 131 & 107 & 24 & 4 & 670 & 29 & 376 \\
\hline 58 & 90 & $\mathrm{E}$ & 200 & 107 & 88 & 19 & 0 & 348 & 0 & 139 \\
\hline 59 & 30 & W & 252 & 117 & 84 & 33 & 21 & 1279 & 231 & 258 \\
\hline 60 & 45 & $\mathrm{NE}$ & 252 & 131 & 69 & 62 & 72 & 2449 & 1081 & 1197 \\
\hline 61 & 50 & $\mathrm{~S}$ & 226 & 128 & 82 & 46 & 93 & 2418 & 1069 & 574 \\
\hline 62 & 30 & $\mathrm{~S}$ & 209 & 117 & 71 & 46 & 37 & 1354 & 217 & 383 \\
\hline 63 & 45 & $\mathrm{E}$ & 191 & 86 & 59 & 27 & 0 & 70,6 & 0 & 129 \\
\hline 64 & 80 & $\mathbf{E}$ & 225 & 115 & 68 & 47 & 16 & 1555 & 256 & 472 \\
\hline 65 & 45 & $\mathrm{NE}$ & 256 . & 124 & 76 & 48 & 30 & 1296 & 304 & 523 \\
\hline 66 & 50 & $\mathrm{E}$ & 253 & 129 & 103 & 26 & 8 & 762 & 75 & 190 \\
\hline 67 & 80 & $\mathrm{E}$ & 252 & 126 & 86 & 40 & 27 & 1319 & 331 & 342 \\
\hline 68 & 90 & SW & 217 & 109 & 84 & 25 & 7 & 606 & 88 & 252 \\
\hline 69 & 45 & $\mathrm{SE}$ & 253 & 143 & 103 & 40 & 34 & 1369 & 378 & 207 \\
\hline 70 & 45 & $\mathrm{SE}$ & 274 & 150 & 95 & 55 & 63 & 2323 & 944 & 599 \\
\hline 71 & 45 & $S$ & 277 & 136 & 94 & 42 & 41 & 1778 & 534 & 422 \\
\hline 72 & 80 & $\mathrm{~N}$ & 213 & 119 & 82 & 37 & 20 & 913 & 319 & 360 \\
\hline 73 & 20 & $\mathrm{E}$ & 250 & 133 & 88 & 45 & 50 & 2239 & 492 & 346 \\
\hline 74 & 15 & $\mathrm{~N}$ & 260 & 144 & 98 & 46 & 78 & 2452 & 1000 & 615 \\
\hline 75 & 50 & $\mathrm{SE}$ & 261 & 134 & 103 & 31 & 18 & 909 & 264 & 86 \\
\hline 76 & 90 & $S$ & 211 & 126 & 108 & 18 & 5 & 454 & 35 & 44 \\
\hline 77 & 90 & SE & 143 & 61 & 27 & 34 & 16 & 1304 & 185 & 135 \\
\hline 78 & 50 & NE & 229 & 102 & 71 & 31 & 0 & 433 & 0 & 56 \\
\hline 79 & 30 & $\mathbf{E}$ & 271 & 128 & 77 & 51 & 14 & 1531 & 134 & 255 \\
\hline
\end{tabular}




\section{RATE OF GROWTH OF THE BRANCHES}

The mean length of the shoots for each week is a convenient and reliable index of their rate of growth. Measurements of the length of these 79 branches were made at seven-day intervals throughout the growing season. Their rate of growth is of interest in the present discussion chiefly because it shows the existence of two distinct cycles

TABLE 2

The Growth of the Main Axis of the Branches. Comparison of Observed Mean Length and Calculated Values. Values for the First Cycle

Computen from Log $\frac{x}{190-x}=.147(t-6)$; For SECOND CyCle

$$
\text { LoG } \frac{x-170}{240-x}=.201(t-17.3)
$$

\begin{tabular}{|c|c|c|c|c|c|c|c|}
\hline \multicolumn{4}{|c|}{ First Cycle } & \multicolumn{4}{|c|}{ Second Cycle } \\
\hline$t$ & $x$ (obs.) & $x$ (calc.) & $\theta$ & $t$ & $(x-170)$ obs. & $(x-170)$ calc. & \\
\hline (wks.) & $(\mathrm{cm})$. & (cm.) & $(\mathrm{cm})$. & (wks.) & $(\mathrm{cm})$. & $(\mathrm{cm})$. & (cm.) \\
\hline 0 & .......... & 22.0 & ...... & 13 & 2.0 & 8.4 & 6.4 \\
\hline 1 & 17.5 & 29.5 & 12.0 & 15 & 17.3 & 17.9 & 0.6 \\
\hline 2 & 32.8 & 39.0 & 6.2 & 17 & 31.3 & 32.6 & 1.3 \\
\hline 3 & 45.6 & 50.5 & 4.9 & 19 & 47.7 & 48.1 & 0.4 \\
\hline 4 & 61.7 & 64.0 & 2.3 & 21 & 58.8 & 59.3 & 0.5 \\
\hline 5 & 81.6 & 79.0 & -2.6 & 25 & 67.3 & 68.0 & 0.7 \\
\hline 6 & 94.9 & 95.0 & 0.1 & 38 & 68.6 & 69.8 & 1.2 \\
\hline 7 & 108.2 & 108.1 & -0.1 & & & & \\
\hline 8 & 121.5 & 126.0 & 4.5 & \multirow{6}{*}{\multicolumn{3}{|c|}{ Root-mean-square deviation }} & 2.55 \\
\hline 9 & 135.9 & 139.5 & 3.6 & & & & \\
\hline 10 & 147.1 & 151.1 & 4.0 & & & & \\
\hline 11 & ............ & $\ldots \ldots \ldots$ & ...... & & & & \\
\hline 12 & 166.1 & 168.0 & 1.9 & & & & \\
\hline 13 & 172.0 & 173.7 & 1.7 & & & & \\
\hline
\end{tabular}

Root-mean-square deviation 4.78

of growth, the first covering the period of 13 weeks in which the most rapid elongation occurred, the second covering the remainder of the growing season. Table 2 shows the observed mean length of the branches at weekly or bi-weekly intervals for 38 weeks and also the length computed from the equation ${ }^{13}$

$$
\log \frac{x}{a-x}=K\left(t-t_{1}\right) .
$$


The actual equation for the first cycle was

$$
\log \frac{x}{190-x}=.147(t-6) .
$$

The equation for the second cycle assumes that the ordinate and the abseissa have been removed to a new point of origin. The new values of $x$ were obtained by subtracting 170 from each of the observed values of $x$. The actual equation was

$$
\log \frac{x-170}{240-x}=.201(t-17.3) .
$$

The graph (fig. 2) shows that the agreement between the computed and observed values of the mean length is satisfactory.

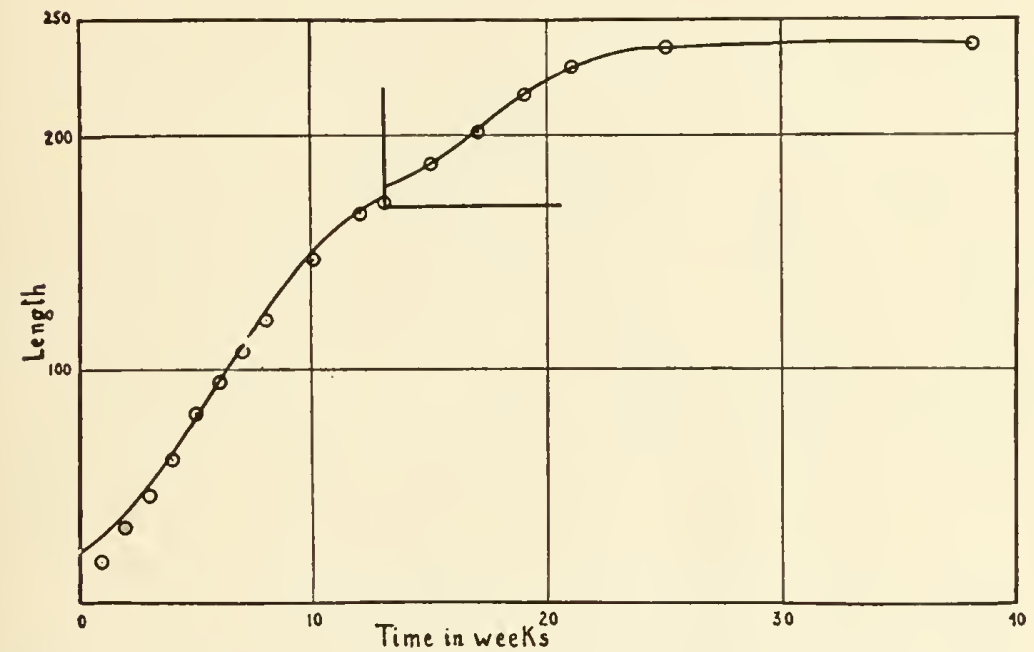

Fig. 2. Growth eurve of the population of branches. The small cireles represent observed mean length of branches, the curves were ealeulated from the equations: first eycle, $\log \frac{x}{190-x}=.147(t-6)$; second cycle, $\log \frac{x-170}{240-x}$ $=.201(t-17.3)$

It may be of interest to note that the appearance of primary laterals was not coineident witl the termination of the first growth cycle. The time at which these laterals first appeared ranged from the third to the seventl week, the mean time being 4.31 weeks from the beginning of the growing season. The relations appear to be different from those described for the growth of roots by Priestley and Pearsall, ${ }^{5}$ who reported that the appearance of secondary or of tertiary roots is concomitant with a lag in the growth curve. 
The validity of the foregoing equation may be tested further by comparing the observed and computed increments in length during the growing season. The foregoing equation, when differentiated, beeomes

$$
\frac{d x}{d t}=k x(a-x)
$$

where $k=\frac{K}{a}$ and the other letters have their former significance. The computed values $\frac{d x}{d t}$ and the observed values of $\mathrm{S}$ are given in table 3. The latter were smoothed by the method commonly used for sueh eases according to the equation

$$
S=1 / 2\left(x_{t-1}+x_{t+1}\right)
$$

TABLE 3

Growth Rate of Apricot Branches as Show by their Weekly

\begin{tabular}{|c|c|c|c|c|c|c|c|}
\hline \multicolumn{4}{|c|}{ First Cycle } & \multicolumn{4}{|c|}{ Second Cycle } \\
\hline$t$ & $\frac{d x}{d t}$ & s & $\theta$ & $t$ & $\frac{d x}{d t}$ & $\mathrm{~s}$ & $\theta$ \\
\hline (wks.) & $(\mathrm{cm})$. & (cm.) & $(\mathrm{cm})$. & (wks.) & (cm.) & (cm.) & (cm.) \\
\hline 0 & 6.8 & 0 & 6.8 & 13 & 34 & 7.7 & -4.3 \\
\hline 1 & 8.7 & 8.8 & -1 & 15 & 6.2 & 7.5 & -1.3 \\
\hline 2 & 10.9 & 10.8 & 1 & 17 & 8.1 & 7.9 & \\
\hline 3 & 13.0 & 10.7 & 2.3 & 19 & 7.0 & 6.3 & \\
\hline 4 & 14.7 & 16.4 & -1.7 & 21 & 4.2 & 5.4 & -1.2 \\
\hline 5 & $15 . s$ & 14.7 & 1.1 & 25 & 9 & 2.1 & -1.2 \\
\hline 6 & 15.9 & 16.6 & 7 & 38 & 1 & 1 & 0 \\
\hline 7 & 15.0 & 13.3 & 1.7 & \multirow{12}{*}{\multicolumn{3}{|c|}{ Root-mean-square deviation }} & \\
\hline 8 & 13.4 & 13.8 & -4 & & & & 1.84 \\
\hline 9 & 113 & 12.3 & 10 & & & & \\
\hline 10 & 9.1 & 11.9 & -2.8 & & & & \\
\hline 11 & 7.1 & 10.4 & -3.3 & & & & \\
\hline 12 & 5.4 & 7.7 & -2.3 & & & & \\
\hline 13 & 4.0 & 7.7 & -3.7 & & & & \\
\hline 14 & 2.9 & 6.8 & -3.9 & & & & \\
\hline 15 & 21 & 7.5 & -5.4 & & & & \\
\hline 17 & 1.1 & 7.9 & 6.8 & & & & \\
\hline 19 & 6 & 6.3 & -5.7 & & & & \\
\hline 21 & .3 & 5.4 & -5.1 & & & & \\
\hline
\end{tabular}
INCREMENT IN LENGTH

Root-mean-square deviation $\quad 3.61$ 
The agreement of the actual and computed values is shown in figure 3. The curves for the two cycles overlap, indicating that the two phases of growth in these branches are not sharply separated from each other. Consequently we must add together the computed values where the curves overlap to approximate the summation of the two cycles. 'The course of these summations is shown by the dotted line, and the observed values agree well with them.

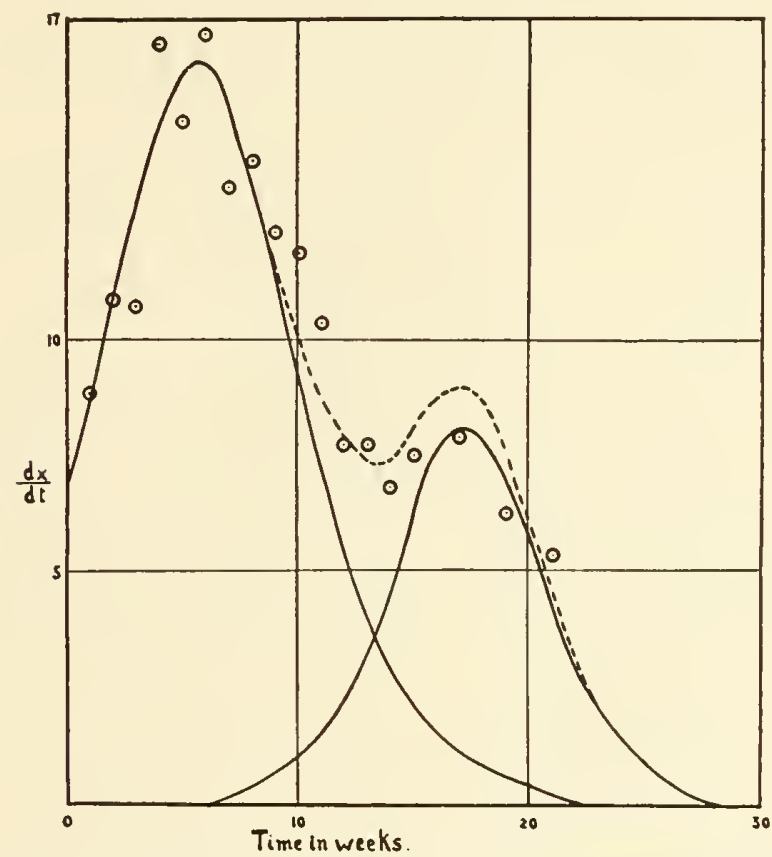

Fig. 3. Growth rate of apricot branches, showing the two overlapping cycles. The curves were calculated from the equations: first cycle, $\frac{d x}{d t}=.00077 x(190-x)$, second cycle, $\frac{d x}{d t}=.00084(x-170)(240-x)$.

The dotted line is the sum of the overlapping portions of the curves. Small circles represent meau weekly increments in length.

These considerations show that the main axis of the apricot branches grew during the entire season in two eycles at perfectly definite rates each of which resembles the rate of an autocatalytic reaction. They show furthermore that the equations may be profitably used to analyze the season's growth. 


\section{MORPHOLOGY OF' THE BRANCHES}

The branches under discussion (fig. 1 gives an idea of the shape they assumed) were selected in early spring at a time when they were only a few centimeters long. They developed from buds near the distal ends of the mother shoots and stood in positions where they had prospects of unhampered development. We may regard this population as representative of shoots which make rapid growth during the first season. Statistics for the salient characters of these branches are given in table 4.

The length of the branches ranged from 137 to $312 \mathrm{~cm}$. and had a mean of $235.95 \pm 2.47 \mathrm{~cm}$. The coefficient of variability is not greater than that commonly encountered in the measurement of biological material.

These branches were less variable with respect to their length than to any other character measured. The frequency distribution of the branches with respect to length is shown in figure 4 . The frequency polygon is fairly symmetrical with respect to its mean and does not depart widely from the type of polygon which represents a random distribution of characters in biological material. In certain respects the variability in elongation is like that previously described ${ }^{9}$ for the shoots of young pear trees.

The total number of nodes on a branch shows a mean of 127.69 with a coefficient of variability of 15.65 . The number of nodes on a branch is closely related to its length, consequently the coefficients of variabihty of length and bud number are not widely different.

The apricot branches have a phyllotaxis of two-fifths. Each node produces from one to three buds only one of which gives rise to a vegetative shoot. The central bud of the group usually derelops, the others remain dormant, at least during the first year.

The production of primary and secondary laterals is one of the important activities of the aprieot branch. The number of primary laterals ranged from 13 to 64 with a mean of $37.00 \pm 1.19$. The distribution of the primary laterals is rather asymmetrical and shows a tendency to skewness toward the higher class values (fig. 5). This distribution is also reflected in the large coefficient of variability (table 4 ). 


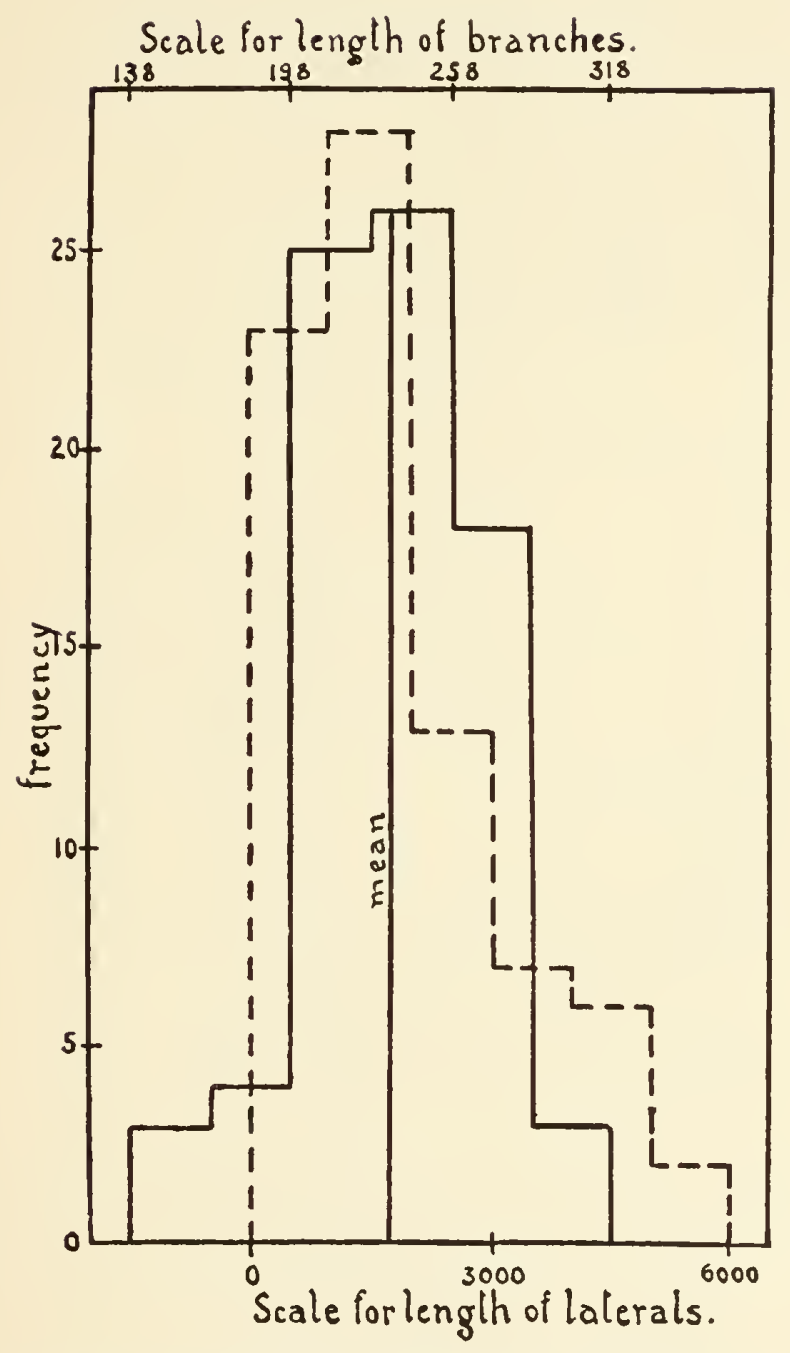

Fig. 4. Frequency distributions for length of branches and combined length of laterals for each branch. The means of the two histograms are superposed. Length of branch, - ; combined length of laterals, - - - 


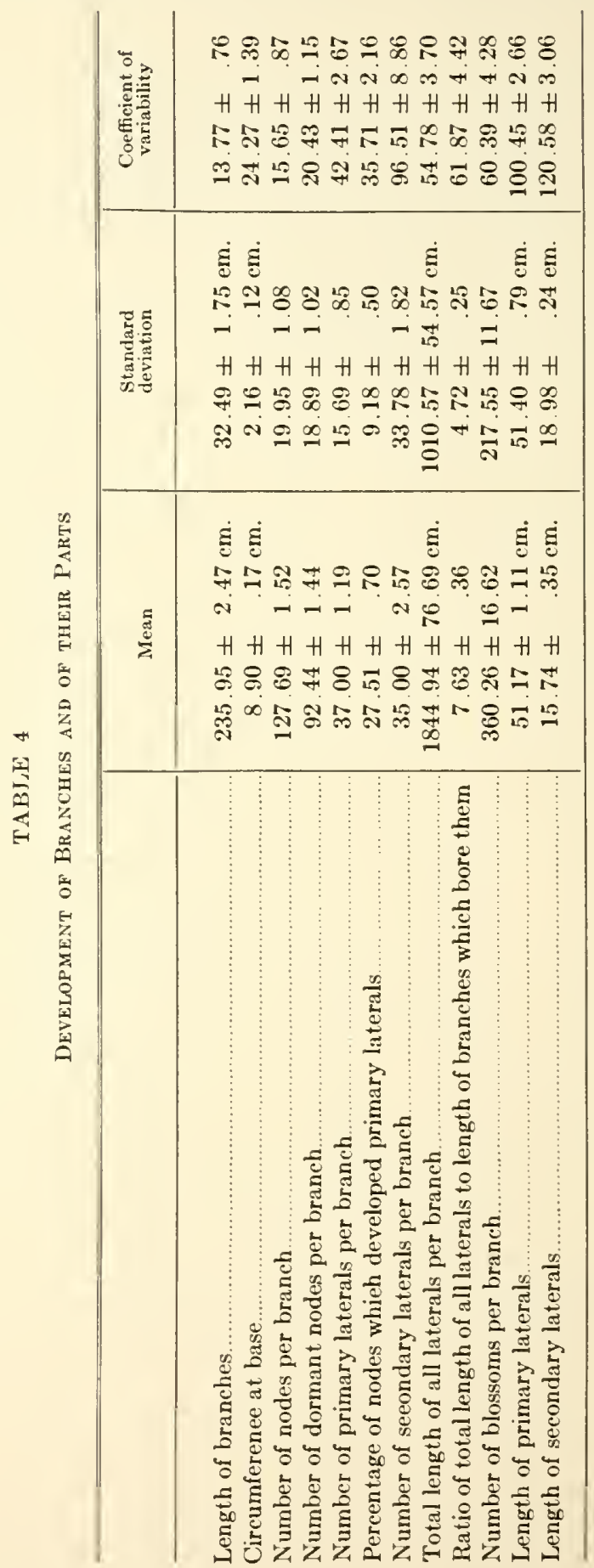


The number of secondary laterals produced on the primary laterals ranged from 0 to 136 with a mean of $35.00 \pm 2.57$ per brancls. The close agreement between the mean number of primary and of secondary laterals may or may not have a significance. Further investigation is necessary before any definite statement can be madc. The distribution of the number of secondary laterals is more asymmetric than that of the primary laterals. Figure 5 shows that the greatest frequency occurs in the class having the lowest value. From this class the frequencies are successively less in the direction of the higher class values. The one-sided distribution is also reflected in the very large coefficient of variability.

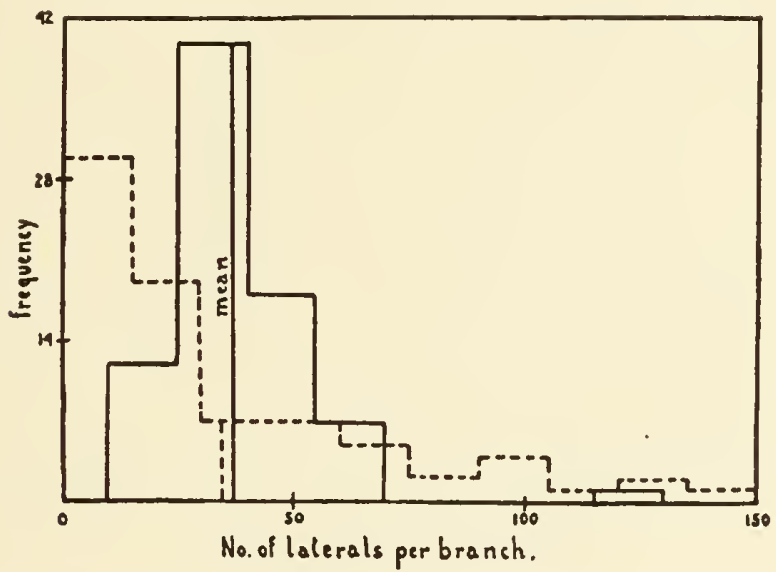

Fig. 5. Frequency distribution for primary and secondary laterals. Primary laterals, -; secondary laterals, - - -

The nature of the variability in the number of laterals directs attention to the nature of the factors which determine their production. An apricot shoot does not arise from a lateral bud except where the conditions which impose dormancy are overcome, hence the number of laterals may be an index of the factors which overcome dormancy. The variability in the production of laterals indicates that the forces which overcome dormancy in the buds are conditioned, not upon factors of environment, but upon factors inherent in the tree. If factors of environment determined the release from dormancy, wc should expect to find a more nearly normal type of distribution.

It is interesting to note that there is not a high degree of association between the length of branch and the total number of laterals which it bore. We may designate number of laterals as $a$, total length 
of laterals as $b$, and length of branch on which they were borne as $c$. The coefficient of gross correlation is

$$
r_{a c}=.337 \pm .067
$$

The coefficient of partial correlation taking into consideration the length of the laterals is

$$
{ }_{a c} r_{b}=-.313 \pm .013
$$

which means that, if all laterals were the same length, there would be a negative association between length of branch and number of laterals produced.

A comparison of figures 4 and 5 shows that the frequency distribution of total length of all laterals per branch is somewhat different from that representing the numbers produced. The ratios of the first to the second character have a mean of $7.63 \pm .36$ (table 4 ). The distribution of total length is not strictly symmetrical, as shown by the graph in figure 4, thele being a distinct tendency for the polygon to skew toward the higher class vahues. In figure 4 the polygon representing distribution of total length of laterals per branch is located in such a position that its mean is superposed on that of the length of branches. The two polygons show a fair degree of correspondence.

The correspondence between the two characters may better be determined by their coefficient of correlation. We may designate number of lateraks per branch as $a$, length of branch on which they were borne as $c$, and total length of laterals as $d$.

$$
r_{c l l}=.700 \pm .040
$$

This indicates a high degree of positive relationship between length of branch and length of laterals produced upon it. Since the number of laterals on branches was itself a variable, we may determine the coefficient of partial correlation, which expresses the correlation in case each branch had the same number of laterals. This is

$$
{ }_{c d} r_{a}=.665 \pm .042
$$

The value of this coefficient indicates a very strong relationship between the growth eapacity of a branch and that of its laterals.

'The forcgoing discussion may be summarized in the following four paragraphs: 
1. The correlations indicate that the longer branches tended to have more laterals and longer laterals, hence it is likely that the position of these shoots on the tree markedly affected the growth capacity of the branches as wholes.

2. The marked difference between the frequency distribution of branches for primary laterals and that for secondary laterals doubtless depends largely on the age factor resulting from the position of the latter on primary laterals; this factor crowded a great part of the latter distribution into the zero class.

3. More generally, the skewness of several distributions suggests a large effect on these characters of a small and unbalanced group of factors conditioning growth.

4. Length of branch seems to have been relatively free from the influence of highly potent factors of asymmetrical effect, but this fact is probably the result in part of the original selection of branches for uniformity of positional growth factors. The farther the members produced get away from the initial leveling effect of that selection, the farther they lapse back into a condition of asymmetric distribution which, as we shall see later, seems to be a general characteristic of the differentiation of the tree.

The graphs together with the illustration (fig. 1) will help to give an idea of the sort of growth that characterizes these apricot branches. The discussion which follows will attempt to discover their quantitative relationships and to analyze growth in the light of these relationships. The work will proceed on the assumption that the size and development of the branches is the result of some dynamic agent acting upon certain raw materials which the tree acquired from its environment. Broadly stated, the problem is to discover something about the process by which the tree forms its diverse parts out of unorganized material.

Data on the influence of location and of direction of growth upon the growth and differentiation of the branches are given in table 5 . The branches are classified with respect to the points of the compass. The 'north' elass comprises branches which were located on the northwest, north, and northeast sides of the trees, and so for other locations. This broad classification necessarily involves some duplication, because, for example, shoots which were recorded as northeast were included both in the north and in the east classes. This duplication undoubtedly operates to minimize differences between the adjoining classes, yet it cannot vitiate comparisons between opposite sides of the trees. 


\begin{tabular}{|c|c|c|c|}
\hline \multirow{7}{*}{ 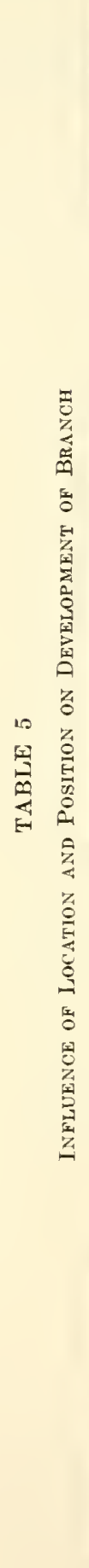 } & 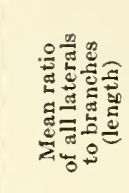 & 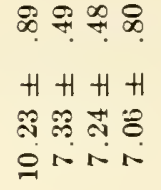 & $\begin{array}{l}\infty \pm 0 \\
\because \\
H \\
H\end{array}$ \\
\hline & 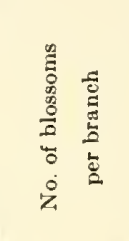 & 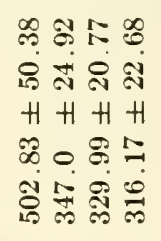 & 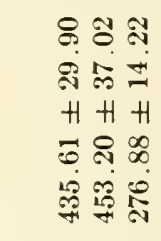 \\
\hline & 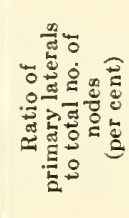 & 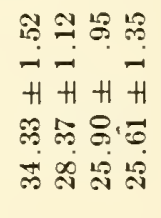 & 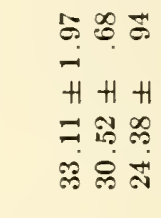 \\
\hline & 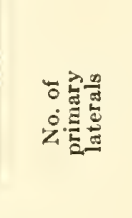 & 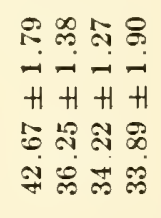 & 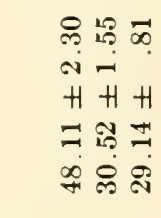 \\
\hline & 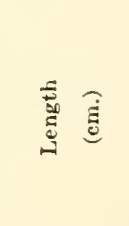 & 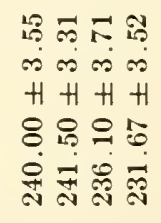 & 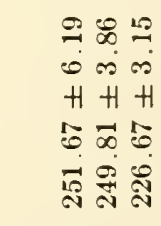 \\
\hline & 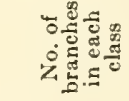 & $\stackrel{20}{\sim}=ㅛ$ & $\sigma \stackrel{\mathrm{N}}{*}$ \\
\hline & 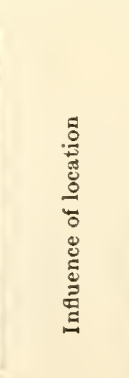 & 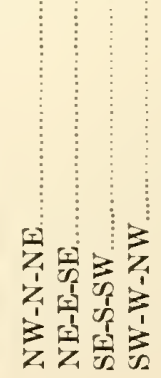 & 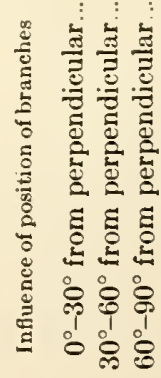 \\
\hline
\end{tabular}


The four classes of branches show no striking differences in mean length attributable to location. The mean number of primary laterals per branch ranged from $33.89 \pm 1.90$ in the west class to $42.67 \pm 1.79$ in the north class. Their difference is $8.78 \pm 2.62$ and may be regarded as significant since $\frac{D}{E_{d}}=3.35$. The means of the other elasses are not significantly different.

The mean ratio of primary laterals to total number of buds (index of lateral production) in the case of the north class indicates a significant difference from those on the other sides of the tree. This difference might have been predicted inasmuch as we have noted that the mean number of primary laterals on branches on the north side of the trees was a maximum while the mean length of the branches on which they grew was approximately the same as those in other classes.

The mean number of blossoms per branch shows no significant difference between different classes except in the case of the north class. The mean for this class is so much greater than the others that we must recognize a real difference in spite of the large probable error attached thereto: the branches in the north class appear to differ from those in the other classes in the possession of more primary laterals (both relatively and absolutely) and in the production of more blossoms. In other words, the process of differentiation seems to have gone farther in these branches. We must not, however, lose sight of the fact that the north class contains only 15 variants and that the reliability of the mean is correspondingly less.

The direction which the main axis of the branch maintains with respect to the perpendicular is known to excrt a marked influence upon its form and function. The second part of table 5 presents some determinations made upon branches classified according to their position at the end of the growing season. I realize that the classification is not strictly accurate, because many branches which were vertical during the first part of the growing season changed their direction as time went on. Weight of the branch and competition for light are among the causes of change of direction. Indecd the greater number of variants in the most nearly horizontal class suggests that the population of this class increased at the expense of the more nearly vertical classes.

No definite statements can be made with respect to the mean length of the three classes of branches although one is inclined to believe that it is actually shorter in the $60^{\circ}-90^{\circ}$ class than in the others. Those 
familiar with the training of fruit trees know that horizontally placed shoots do not attain so great a length, in the same time, as do upright shoots.

The number of primary laterals was considerably greater on the upright branches than upon those of the other two classes, and least upon those in the $60^{\circ}-90^{\circ}$ elass. I think it only logical to assume that these differences refleet in large measure the effects of some growthinhibiting agency whose action on horizontal shoots and cuttings has been previously described. ${ }^{10,11}$ The development of laterals on these branches would also be influenced by the degree of success attained by the branch in its competition for light and by other growth promoting agencies.

The ratio of primary laterals to the total number of nodes on the branches is eonsiderably smaller in the $60^{\circ}-90^{\circ}$ elass, indicating that the development of lateral buds is in some way retarded on these branehes.

Another relationship which shows the effect of the direction of growth is that which exists between the length of the branch and the total length of all laterals. The ratio between these quantities ought to indicate the relative differentiation which a branch has undergone. These figures show that the most nearly upright branches had the highest ratio. Those which stood in the intermediate position, $30^{\circ}-60^{\circ}$, had a somewhat smaller ratio, but those most nearly horizontal had the smallest ratio. This condition ealls attention to the usual differences in development between orthotropic and plagiotropic branches. The differences have been frequently inentioned in the literature and have been ascribed ${ }^{11}$ to the aetion of a growth-inhibiting substance in the branch. Plagiotropic shoots are typically dorsiventral while orthotropic shoots are radial. This means that the buds on one side of the plagiotropic shoot are the only ones which reach any extensive development. As a result, the ratio of prinary laterals to branch is smaller than in the case of upright shoots. The reasons for the smaller ratio may be two: first, the actual number of laterals is less; second, the laterals which develop are shorter. From an inspection of the fignres in table 5 it seems that the first mentioned condition is principaly responsible for the smaller ratio. It appears from data given in table 6 that the branehes on the north side of the tree were somewhat less variable in the ratio of active to dormant nodes, and that the plagiotropic branches were more variable in this character than the orthotropic branches. 
TABLE 6

Effects of Location and Position upon the Percentage of Nodes which Produced Primary Laterals

\begin{tabular}{|c|c|c|c|}
\hline INFLUENCE OF LOCATION & Mean & $\begin{array}{l}\text { Standard } \\
\text { deviation }\end{array}$ & $\begin{array}{l}\text { Coefficient of } \\
\text { variability }\end{array}$ \\
\hline $\mathrm{NW}-\mathrm{N}-\mathrm{NE} .$. & $34.33 \pm 1.52$ & $8.73 \pm 1.07$ & $25.44 \pm 3.33$ \\
\hline NE-E-SE ... & $28.37 \pm 1.12$ & $10.46 \pm .78$ & $36.87 \pm 3.14$ \\
\hline SE-S-SW ................... & $25.90 \pm .95$ & $9.07 \pm .67$ & $35.02 \pm 2.91$ \\
\hline SW-W-NW & $25.61 \pm 1.35$ & $8.47 \pm .95$ & $33.07 \pm 4.09$ \\
\hline $\begin{array}{c}\text { InfLuence of Position } \\
\text { of BRanches }\end{array}$ & & & \\
\hline $0^{\circ}-30^{\circ}$ from perpendicular. & $33.11 \pm 1.97$ & $8.75 \pm 1.39$ & $26.43 \pm 4.49$ \\
\hline $30^{\circ}-60^{\circ}$ from perpendicular. & $30.52 \pm .97$ & $7.44 \pm .68$ & $24.38 \pm 2.37$ \\
\hline $60^{\circ}-90^{\circ}$ from perpendicular. & $24.38 \pm .94$ & $9.08 \pm .67$ & $37.24 \pm 3.10$ \\
\hline
\end{tabular}

The number of blossoms which each class of branches produced in the following spring shows considerable variation (table 5). Here the difference between the $60^{\circ}-90^{\circ}$ branches and the others is of a magnitude that seems to be significant. Clearly, we cannot explain the difference by the fact that these branches were somewhat shorter than those of the other classes. Moreover, the difference in the number of blossoms should not be referred to the length of the branch, bnt to the total length of laterals on the branches of the three classes. J. P. Bennett has suggested that the ratio of blossoms to unit of lateral is greater in the $60^{\circ}-90^{\circ}$ class than in the others. The data given in table 7 show this to be true. The $0^{\circ}-30^{\circ}$ elass of branches produced a combined

\section{TABLE 7}

Relation of the Direction of Growth of Branches on the Ratio of Siloots to Blossoms

\begin{tabular}{|c|c|c|}
\hline & $\begin{array}{l}\text { Mean length of } \\
\text { all laterals on } \\
\text { the branch } \\
\mathrm{cm} \text {. }\end{array}$ & $\begin{array}{l}\text { No. of blossoms } \\
\text { per } 100 \mathrm{~cm} \text {. of } \\
\text { laterals }\end{array}$ \\
\hline Branches $0^{\circ}-30^{\circ}$ from perpendicular. & 2619 & 15.4 \\
\hline Branches $30^{\circ}-60^{\circ}$ from perpendicular. & 2455 & 18.2 \\
\hline Branches $60^{\circ}-90^{\circ}$ from perpendicular. & 1313 & 20.9 \\
\hline
\end{tabular}

length of laterals which was about twice that of branches in the $60^{\circ}-90^{\circ}$ class. The number of blossoms per $100 \mathrm{~cm}$. of laterals was greater, however, in the $60^{\circ}-90^{\circ}$ class. This suggests that conditions 
in the $60^{\circ}-90^{\circ}$ class were more favorable for fruit-bud formation and decidedly less favorable for vegetative growth. The opposition between the vegetative and the reproductive activities of plants is so well known that extended comment is not necessary. The data here presented give a quantitative expression of the relationship for the apricot branches.

\section{DORMANCY AND GROWTH OF BUDS ON THE BRANCHES}

The average number of nodes on the branches measured was $127.69 \pm 1.52$ and the standard deviation was $19.95 \pm 1.08$ (table 4 ). The type of the distribution of nodes (fig. 6) and that of branch length are necessarily more or less similar, and both are skewed toward the lower elass ranges.

The mean distance between nodes was approximately $1.8 \tilde{\mathrm{cm}}$., but in certain regions, especially near the proximal end, they were more closely grouped than in others. There is no doubt that the rate of growth of the main branch has an effect in spacing the nodes on its axis. The differences in spacing have not been ineasured for the present study.

Approximately 30 per cent of the nodes on the branch produced lateral shoots during the period when the branch was still making its first season's growth, while the rest remained dormant. The stoichiometry of the branch depends to a large extent upon the way in which the buds react, i.e., whether they remain dormant or grow. It is therefore important to investigate the question of growth and dormancy in these buds.

Each bud may be regarded as a center of potential energy in which there is located a quantity of labile compounds of carbon and nitrogen. Under certain eonditions, processes of growth are initiated in the course of which these energy centers produce new structures. The amount of material synthesized at each energy center and its relation to the rest of the system may, to some extent, serve as an index of those dynamic factors with which we have to deal.

The ratio of primary laterals to all nodes expressed as a percentage gives the most obvious expression of lateral production. This ratio has been determined for each branch (table 4). The mean of all ratios is $27.51 \pm .70$. The frequency distribution of these ratios is shown in figure 7 . 


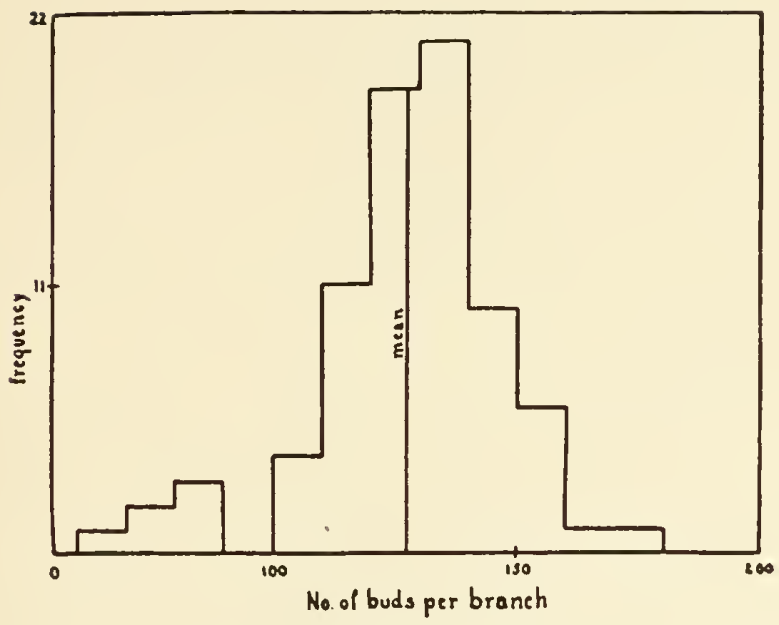

Fig. 6. Frequency distribution for number of nodes.

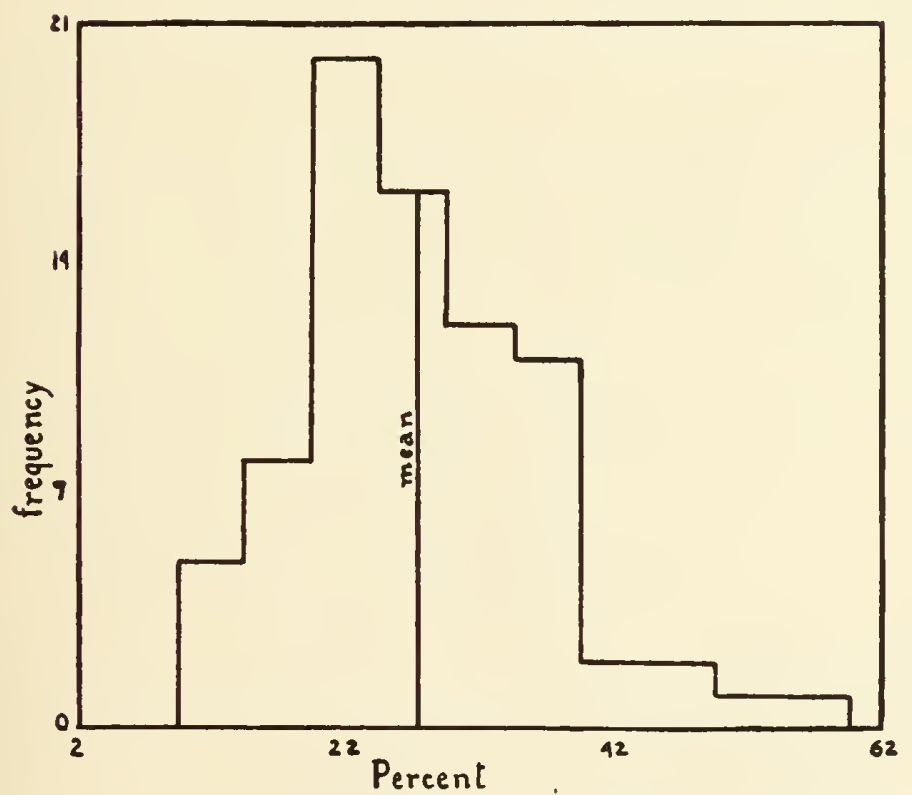

Fig. 7. Frequency distribution showing per cent of nodes from which primary laterals were produced. 
This histogram shows some very important things about the variability in the percentage of nodes which produce primary laterals. In the first place, the skewness of the figure is pretty good evidence that the percentage of buds which developed was not entirely due to purely chance factors. Had that been the case the figure more nearly would resemble the normal eurve of errors. In the second place, we find upon referring to table 4 that the coeffieient of variability for the percentage of nodes which produced primary laterals is more than twice as large as the same constant of variability for the total number of buds.

These relationships seem to indicate that this problem of differentiation is not entirely simple; that no one factor determines whether a bud shall grow or remain dormant; but rather that the factors which overcome dormancy are much more variable in their effects than those which determine the formation of nodes upon the branch. It was seldom that more than 50 per cent of the nodes on a branch produced laterals and the modal value was only 24.29 per cent. Some of the conditions which operated to cause this variability in overcoming dormancy of the buds will be pointed out later.

In an earlier paragraph attention was ealled to the effect which location and position of the branch have on various phases of development. Table 6 also shows the effeet of these factors upon the percentage of nodes which produced primary laterals. It will be seen that the branches on the north side of the trees produced a greater percentage of laterals than those on the other sides of the trees. The mean is appreciably larger than the means of other groups and the coefficient of variability is considerably smaller. The mean percentages of the other three groups show no significant differences.

When the branches are classified according to their declination from a perpendicular line we find differences in the pereentages of buds which developed. The percentages in the classes $0^{\circ}-30^{\circ}$ and $30^{\circ}-60^{\circ}$ are not significantly different either in magnitude or variability, but the $60^{\circ}-90^{\circ}$ elass was significantly lower as to its mean and also inore variable.

The pereentage of dormancy in different regions on the branches is another measure of the distribution of growth stimuli. The nodes on the branches were tabulated in groups of 20 each and the percentage of dormancy determined for each group. Group 1-20 is the proximal group and group 161-180 is the distal group. The figures as given in table 8 show that great differences in the percentage of 
dormancy existed in different regions. The lowest percentage of dormancy existed in group 21-40, in which only 19.05 per cent of the buds failed to develop. From this region the percentage of dormancy increased to 94.59 in group 81-100, dropped slightly in the next group, and rose gradually in succeeding groups to complete dormancy in the last group.

TABLE 8

Percentage of Dormancy in Nones on Different Regions of the Branches

\begin{tabular}{l|l|l|l|l|l|l|l|l|l|l|l|l}
\hline & \multicolumn{1}{|c}{ Groups } \\
\hline $\begin{array}{c}\text { Percentage of } \\
\text { dormancy......... }\end{array}$ & 79.68 & 19.05 & 61.96 & 76.86 & 94.59 & 89.49 & 96.62 & 96.43 & 100.0 \\
\hline
\end{tabular}

It is evident that the forces which broke the dormaney of the buds on these apricot shoots were not distributed in a regular gradient. The lowest group had a ligh percentage of dormaney, while the next group had the lowest percentage. Clearly we cannot refer the cause of such a distribution either to a simple axial gradient or to an age factor, except in the distal part of the branches. The data under discussion lead directly to the next point, viz., the number and position of primary laterals.

The relationship between the length of the branch and the number of nodes from which primary laterals were produced is a problem of some biological importance. The best method of expressing these relationships is by a series of correlations. The correlation coefficients ought to show whether a long or a short branch tends to produce more primary laterals. If we let $l=$ the length of a branch; $n=$ the number of nodes on a branch; and $d=$ the number of nodes which produced primary laterals, the gross coefficients of correlation are

$$
\begin{aligned}
& r_{l d}=.479 \pm .058 \\
& r_{n d}=.403 \pm .060 \\
& r_{n l}=.836 \pm .020
\end{aligned}
$$

There is a significant degree of correlation between the number of nodes which produced primary laterals and the length of the branch. This means that longer branches have a tendency to produce more primary laterals than short branches, and speaks against the idea that a branch which attains more than average length is thereby incapacitated for producing a proportionally large number of laterals. There is nothing like a one to one correlation between length (or number of 
nodes) and number of primary laterals, though the correlation is positive and significant. The correlation between length of branch and number of laterals may result largely from the close correlation between length of branch and total number of internodes on the branch. By calculating the coefficient of partial correlation we may eliminate the effect of the latter relation. The value is

$$
{ }_{l d} r_{n}=.283 \pm .070 \text {. }
$$

We may interpret this coefficient to mean that the greater length of branch favors lateral production, entirely apart from a greater number of nodes. The coefficient of partial correlation has a magnitude four times that of its probable error and may be regarded as significant. We may interpret it to mean that there is a small, but positive, degree of relationship between these two variables.

We may ask, Does the proportionate number of nodes producing laterals tend to change significantly with change in total number of nodes? The obvious suggestion, that we find the correlation between total number of nodes and percentage of nodes producing laterals, seems to involve the introduction of "spurious correlation of indices."

We may therefore compute the correlation between the number of primary laterals and the deviation of this number from its probable value

$$
r_{n z}=\frac{r_{n d}-\frac{V_{n}}{V_{d}}}{\sqrt{1-r^{2}{ }_{n d}+\left(r_{n d}-\frac{V_{n}}{V_{d}}\right)^{2}}}
$$

In this case $V_{n}$ and $V_{d}$ are the coefficients of variability of the number of nodes and of the numbers of primary laterals respectively.

$$
r_{n z}=-.082 \pm .075
$$

The value of this coefficient is close to zero and, in view of the magnitude of its probable error, cannot be regarded as indicative of any correlation. It slows that there is little or no real difference in the proportionate eapacity of branches with different numbers of nodes to produce primary laterals. In otler words, there is no correlation between the number of primary laterals and the deviation from their probable number.

'Tle lack of any marked causal relationship between the percentage of dormancy and the lengtly of primary laterals is also indicated by the coefficient of correlation between these two characters. It has the very 
low value of $r=.061 \pm .076$ and cannot be regarded as significant.

In figure 18, there is a presentation of the general problem of correlation in the apricot branch. The length and the number of primary laterals show a fairly high positive correlation with the length of the branches, and about the same degree of correlation with similar characters of the secondary laterals. The total length of all laterals bears a very high degree of positive correlation with the length of the branch.

\section{DIFFERENTIATION}

\section{Configuration of Laterals on Branches}

The process of differentiation as manifested by the growth of primary and secondary laterals is one of the important aspects of this study. We are concerned, not alone with the activities which result in the formation of the main axis of the branch, but with the formation of its subsidiary shoots. These subsidiary shoots are morphological characters which go to make up the entities with which we are dealing. From the standpoint of the fruit grower they are of primary interest because they determine, to a large extent, the capacity of a branch to produce fruit. The importance of this process in Sea Island cotton has recently been discussed by Mason. ${ }^{*}$

The various groups of primary laterals on the apricot branches were so well delimited that it was an easy matter to deterinine and measure their salient characters. The data are summarized in table 9 . Group I refers to the group nearest the proximal end of the branch, and group III to the group nearest the distal end (fig. 1). The length of the groups diminishes as we pass toward the distal end of the branches, and the space between groups increases.

The superior development of the laterals in Group I is most strikingly shown by a comparison of the total length of all primary laterals in that group with the length of primary laterals in other groups. In this respect Group I produced six times as much as Group II and seventeen times as much as Group III, while Group II produced only three times as much as Group III. The total number of nodes on primary laterals follows rather closely the ratios of total length.

The number of secondary laterals per branch borne upon the primary laterals of each group differs still more widely, as might be expected, since primary laterals must attain a certain size and stage of maturity before they produce secondary laterals. 


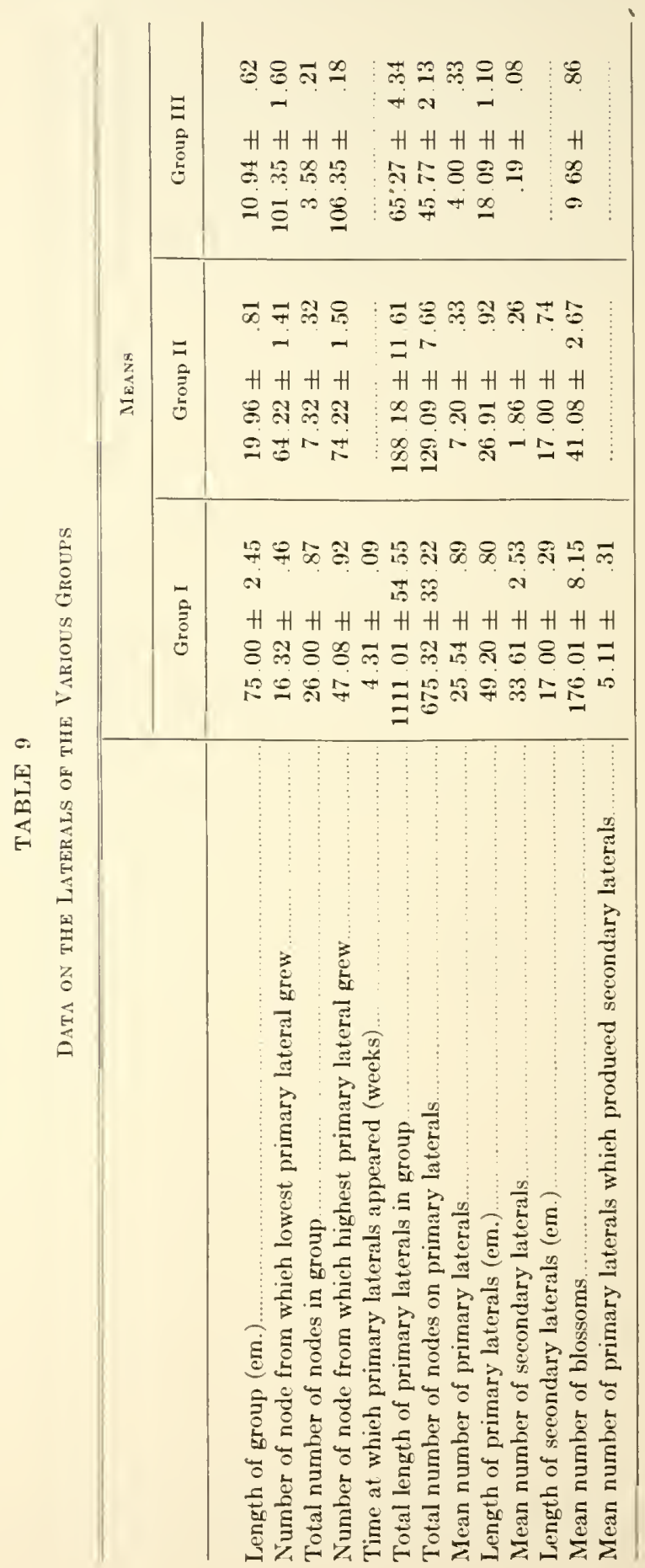


The time at which the first primary laterals were found upon the branches was recorded only for those of Group I. At that time ( 4.31 weeks) the mean length of the branches was about $70 \mathrm{~cm}$. and they were approaching their period of most rapid growth.

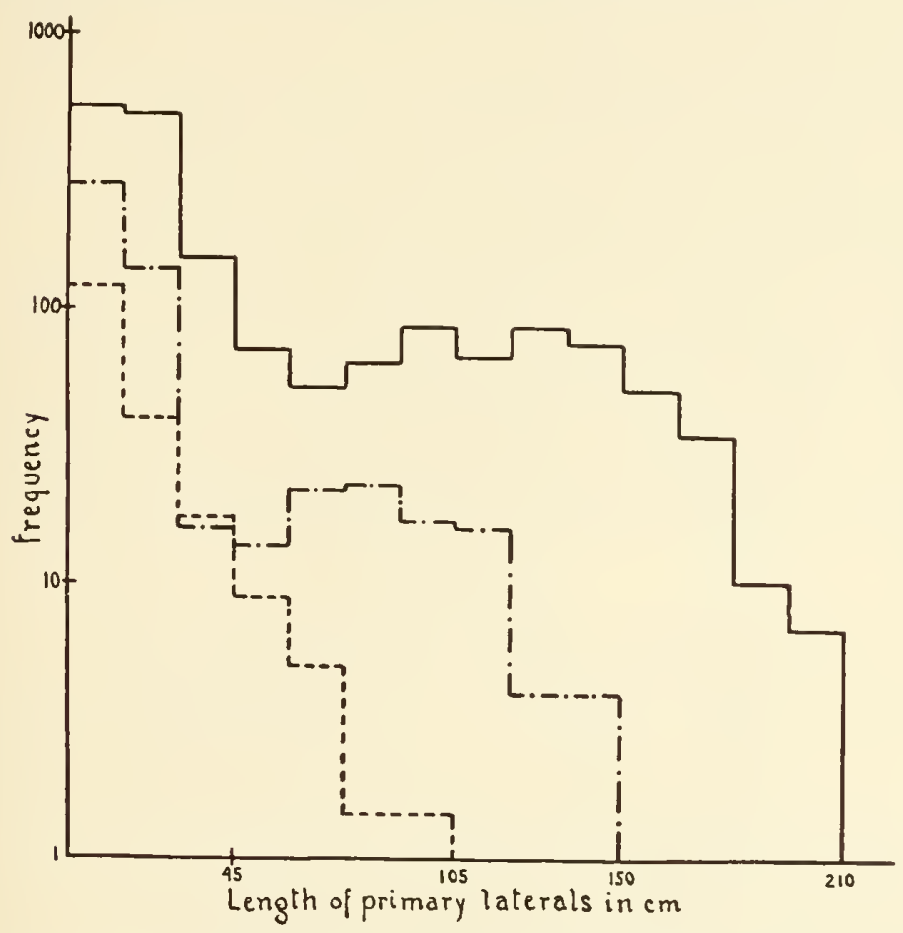

Fig. 8. Frequency distributions for length of primary laterals in the three groups plotted on logarithmic seales. Group I, _-; Group II, _... - ; Group III, - - -

\section{Primary Iaterals}

The frequency with which laterals of various lengths were produced is a matter of importance because it shows something of the ability of the main axis of the branches to produce new material. It is plain that the kind as well as the number of laterals produced is an index of the differentiation which occurred.

It has already been shown (figure 4) that the total length of all laterals, primary and secondary, per braneh gives a skewed distribution. The figures in table 4 show that the coefficient of variability of the measurements of total length was rather ligh and indicate that the length distribution is subject to considerable fluctuation.

The histograms of length distribution for 2528 individual primary laterals (fig. 8) in the three groups are extremely asymmetric with 
very high frequeneies in the classes of shorter laterals. To appreciate fully the asymmetry of these distributions the reader must recolleet that the frequencies are plotted on a logarithmic seale. The asymmetry appears to increase as one passes from Group I to Group III. Having seen the graphs representing the frequency distribution of laterals. the reader will appreciate the data in table 10 showing the mean length and variability of laterals of the various groups. The distributions show that the numbers of short laterals in the several groups are not governed by the laws of ehance-they are indeed so far from what would oceur in an approximately normal eurve of errors that we must conclude that length of primary laterals is determined by some very definite factor so fixed in its action that the law of chance is practically eliminated. It is evident that more short laterals occurred in Groups II and III than in Group I, a result due in part, undoubtedly. to the age factor. Many of the laterals in these groups might have beeome longer if the growth eycle of the tree had not terminated when it did.

TABLE 10

Length of Laterals on Apricot Branches

\begin{tabular}{|c|c|c|c|c|}
\hline & $\begin{array}{l}\text { No. of } \\
\text { vari- } \\
\text { ants }\end{array}$ & $\begin{array}{l}\text { Mlean } \\
\text { (cm.) }\end{array}$ & $\begin{array}{l}\text { Standard } \\
\text { deviation } \\
(\mathrm{cm} .)\end{array}$ & $\begin{array}{c}\text { Coeffieient } \\
\text { of variability }\end{array}$ \\
\hline Primary laterals, Group I.. & 1796 & $49.20 \pm$ & $50.36 \pm .57$ & $102.36 \pm 2.38$ \\
\hline Primary laterals, Group II.. & 538 & $26.91 \pm .92$ & $31.52 \pm .65$ & $117.13 \pm 4.65$ \\
\hline Primary laterals, Group III & 194 & $18.09 \pm 1.10$ & $22.75 \pm .78$ & $125.76 \pm 8.79$ \\
\hline Primary laterals, all groups. & 2528 & $42.07 \pm .62$ & $46.50 \pm .44$ & $110.53 \pm 1.95$ \\
\hline Secondary laterals, Group I & 2276 & $17.00 \pm$ & $20.22 \pm 20$ & $118.94 \pm 2.33$ \\
\hline Secondary laterals, Group II & 156 & $17.00 \pm$ & $13.72 \pm .52$ & $80.70 \pm 4.6 \mathrm{~S}$ \\
\hline
\end{tabular}

As a further measure of the amount of differentiation we nay determine the eases in which primary laterals produeed secondary laterals. We have seen in table 4 that the mean number of secondary laterals per braneh was 35 and table 9 shows that praetieally all of them arose on primary laterals of Group I. The number of primary Jaterals which produced secondary laterals was $5.11 \pm .31$ per branch. and the average number of seeondary laterals on each was about six. As will be shown later, there is a high degree of positive correlation between the mean numbers per branch of primary and secondary laterals, which indicates that the same tendeney toward differentiation is shared by branehes and their laterals. 
The total number of blossoms on the primary laterals shows differences somewhat similar to those of other characters. The number of blossoms on Group I was about four times as great as on Group II, and about eighteen times as great as on Group III.

\section{TABLE 11}

Length of Primart Laterals on each Daughter Shoot

$X=$ ordinal position of the laterals.

$Y=$ average length of $y_{x-1}, y_{x}, y_{x+1}$.

\begin{tabular}{rcrrrr}
$\mathrm{X}$ & $\begin{array}{c}\mathrm{Y} \\
(\mathrm{cm} .)\end{array}$ & $\mathrm{X}$ & $\begin{array}{c}\mathrm{Y} \\
(\mathrm{cm} .)\end{array}$ & $\mathrm{X}$ & $\begin{array}{c}\mathrm{Y} \\
(\mathrm{cm} .)\end{array}$ \\
2 & \multicolumn{1}{c}{. } & 53 & 10.95 & 104 & 1.05 \\
5 & .19 & 56 & 9.58 & 107 & 2.87 \\
8 & 1.94 & 59 & 18.08 & 110 & 1.88 \\
11 & 11.42 & 62 & 13.28 & 113 & 1.00 \\
14 & 12.50 & 65 & 9.13 & 116 & 1.21 \\
17 & 18.22 & 68 & 6.00 & 119 & .98 \\
20 & 26.36 & 71 & 2.92 & 122 & .74 \\
23 & 41.64 & 74 & 1.46 & 125 & .38 \\
26 & 52.40 & 77 & 1.08 & 128 & .54 \\
29 & 55.59 & 80 & .58 & 131 & .20 \\
32 & 42.50 & 83 & 1.78 & 134 & .0 \\
35 & 29.60 & 86 & .84 & 137 & .08 \\
38 & 21.80 & 89 & 1.51 & 140 & .05 \\
41 & 15.01 & 92 & 1.40 & 143 & .04 \\
44 & 8.72 & 95 & 1.22 & 146 & .0 \\
47 & 7.78 & 98 & .63 & 149 & .05 \\
50 & 8.37 & 101 & 2.41 & 152 & .05
\end{tabular}

We may attempt first to get a general idea of the number, position, and length of the primary laterals upon the branches under consideration. It has already been stated that the number of primary laterals ranged from 13 to 64 per branch with a mean of 37 . The position of the primary laterals and the mean length of laterals in various positions may next be ascertained. These data are presented in table 11. The ordinal number of each primary lateral was determinea by ascertaining the number of the node from which it grew, counting from the proximal (basal) end of the branch. The value of $Y$ (the length of successive laterals) is recorded for the lateral in position $X$. In order to simplify the table, the mean length of three laterals is given for every third lateral; for example, the length $Y$ was obtained by taking the average of $y_{x_{x-1}}, y_{x}$ and $y_{x_{+1}}$. The length of lateral 17 is accordingly the average length of laterals 16.17 , and 18 .

The nodes at the base of the branches produced no laterals, or very short laterals. The length of the laterals was progressively longer as 
the distance from the proximal end increased up to approximately lateral 30, then decreased rather rapidly to lateral 45. A second maximum oceurred near lateral 60. From lateral 70 on to the distal end of the branch, the laterals were exceedingly variable in length, and the average for any given position is small. This may be, in part, because of the fact that they were produced later in the growing season and their growth was therefore terminated sooner by the approach of winter dormancy.

Casual observation will show that the primary laterals oceur in well defined groups on each branch and that a true impression of the differentiation is not to be obtained readily from the figures presented in table 11. Most of the branches had three groups of primary laterals. The group nearest the proximal end of the branch was the largest, and, as already intimated, produced the longest primary laterals (ef. fig. 1). Above the first group, about 20 buds remained dormant, and the second group was inferior both in number and in length of laterals.

An analysis of the mean length of the primary laterals will be presented later in a discussion of certain dynamical aspects of their growth. We will now compare the primary laterals in the scveral groups with respect to their more obvious features.

The primary laterals in a group are rather symmetrically arranged accolding to length. The longest laterals are at the center of the groups and the lengths of other laterals diminish as one passes from the center to either end of the group. The rate at which the lengths of successive laterals diminish suggests a logarithmic eurve.

All the groups were now superposed in such a way that the central lateral of each Group I fell upon the same point. If we take node 48 as the midpoint for the laterals of Group I, and arrange the data so that the actual centers of Group I coincide for all branches, we can easily get the mean length of the primary laterals for each node, upon the basis of a uniform arrangement. Table 12 gives the values so obtained. If this adjustment also results in placing the laterals of Groups II and III in symmetrically shaped groups, it might lend additional support to the assumption that the development of primary laterals is the outcome of a definite physiological function of growth. As a matter of fact, this is just what happens. The grouping of laterals in Group II results, on a smaller scale in the same arrangement as that in Group I. The arrangement of laterals in Group III is less strikiug on account of their shortness and because of their great variability, yet it is fairly definite. 


\section{TABLE 12}

Mean Length of Primary Laterals after Adjusting Positions so that Bud-position 48 Was the Center of Group I

$$
X=\text { ordinal bud-position. }
$$

$Y=$ mean of $y_{x-1}, y_{x}$, and $y_{x+1}$.

$\begin{array}{rrrrrr}\mathrm{X} & \mathrm{Y} & \mathrm{X} & \mathrm{Y} & \mathrm{X} & \mathrm{Y} \\ 5 & 0.0 & 59 & 16.69 & 113 & 1.08 \\ 8 & 0.09 & 62 & 12.52 & 116 & 1.49 \\ 11 & 0.46 & 65 & 10.00 & 119 & 1.54 \\ 14 & 1.57 & 68 & 7.65 & 122 & 1.09 \\ 17 & 2.12 & 71 & 11.10 & 125 & 1.97 \\ 20 & 3.26 & 74 & 7.57 & 128 & 1.79 \\ 23 & 6.36 & 77 & 10.02 & 131 & 1.36 \\ 26 & 7.68 & 80 & 10.09 & 134 & 1.06 \\ 29 & 10.60 & 83 & 8.08 & 137 & 1.40 \\ 32 & 22.64 & 86 & 7.12 & 140 & 0.32 \\ 35 & 28.92 & 89 & 2.88 & 143 & 0.28 \\ 38 & 26.49 & 92 & 1.40 & 146 & 0.0 \\ 41 & 39.11 & 95 & 2.51 & 149 & 0.0 \\ 44 & 44.03 & 98 & 1.11 & 152 & 0.12 \\ 47 & 44.61 & 101 & 1.31 & 155 & 0.12 \\ 50 & 38.86 & 104 & 1.27 & 158 & 0.0 \\ 53 & 28.39 & 107 & 1.20 & 161 & 0.08 \\ 56 & 17.07 & 110 & 1.00 & & \end{array}$

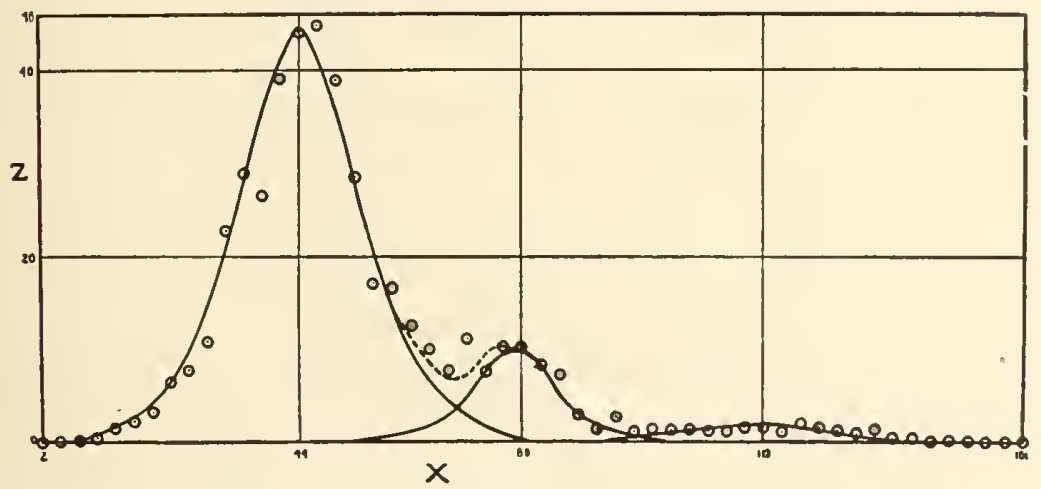

Fig. 9. Curves showing the cyclie nature of the three groups of primary laterals. $X$, ordinal position of laterals; $Z$, length of laterals. The curves were computed from the equations:

$$
\begin{aligned}
& \text { Group I ............................... } Z_{1}=.000177 y_{1}\left(380-y_{1}\right)
\end{aligned}
$$

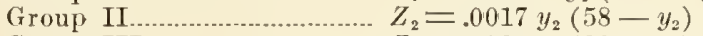

$$
\begin{aligned}
& \text { Group III............................. } Z_{3}=.0024 y_{3}\left(20-y_{3}\right)
\end{aligned}
$$

The broken line represents the summation of overlapping portions of the curves of Groups I and II. Small circles represent mean lengths of laterals in the various ordinal positions after positions had been shifted to bring the center of each Group I to the same point. 
Group I laterals had a maximum mean length of $\$ 4.6 \mathrm{~cm}$. at node 48. The upper range of Group I overlaps the lower range of Group II, and it is necessary to recognize the overlapping values in studying the groups. This aspect will be discussed below. Node 70 probably marks the point near which Group I ends and Group II begins.

Group II laterals appear to reach a maximum mean length of about $10 \mathrm{~cm}$. near node 80 , from which point the length decreases to another minimum near node 98.

Group III appears to have a maximum mean length of laterals near node 119 from which the length decreases to near node 160 .

The important feature, for our present purposes, is that the mean lengths of primary laterals fall into three distinct groups. When the values are plotted on a scale in which ordinates are the lengtlis of the several laterals and abscissae are the ordinal positions of laterals on the branch, they form three symmetrical, overlapping curves (fig. 9).

If we assume that the cyclic growth of the primary laterals is in some way similar to the eyclic growth in length of the branch which bears them, we may proceed to examine the data by the method already used. The situation may be simplified by assuming that the forces which produce the branches produce in the same way the primary laterals. The summations of length of laterals, beginning at the base of the branch, should therefore give a curve somewhat like that representing the increasing length of the branches, shown in figure 2. This was found actually to be the case, and the three groups of laterals could readily be distinguished. The observed values agreed elosely with an equation of the general form

$$
\log \frac{y}{a-y}=K\left(x-x_{1}\right)
$$

where $y=$ length at any node $x ; x_{1}=$ the node at which $y$ had attained half the length of $a$ for the cycle; $a=$ the maximum (limiting) value of $y$; and $K=$ a constant.

If the lengths of the laterals be regarded as increments at unit distances on the branch, starting at the proximal end, then the differential form of the foregoing equation onght to express their lengths for each nodal position. The differential form of the above equation is

$$
Z=\frac{d y}{d x}=k y(a-y)
$$

Here $k=\frac{K}{a}$ 
With the aid of the table prepared by Robertson, ${ }^{13}$ the values of $Z$ shown in table 13 were computed.

$$
\begin{aligned}
& \text { Group I …..................... } Z_{1}=.000177 y_{1}\left(380-y_{1}\right) \\
& \text { Group II ........................... } Z_{2}=.0017 y_{2}\left(58-y_{2}\right) \\
& \text { Group III …..................... } Z_{3}=.0024 y_{3}\left(20-y_{3}\right)
\end{aligned}
$$

TABLE 13

Mean Length of Primary laterals Showing their Cyclic Arrangement.

\begin{tabular}{|c|c|c|c|c|c|c|c|c|}
\hline \multicolumn{3}{|c|}{ Group I } & \multicolumn{3}{|c|}{ Group II } & \multicolumn{3}{|c|}{ Group III } \\
\hline $\mathrm{x}$ & $\begin{array}{c}\text { observed } \\
\mathbf{Y} \\
(\mathrm{cm} .)\end{array}$ & $\begin{array}{l}\text { calc. } \\
Z_{1} \\
(\mathrm{~cm} .)\end{array}$ & $\mathrm{x}$ & $\begin{array}{c}\text { observed } \\
\mathbf{Y} \\
(\mathrm{cm} .)\end{array}$ & $\begin{array}{l}\text { calc. } \\
Z_{2} \\
(\mathrm{~cm} .)\end{array}$ & $\mathrm{x}$ & $\begin{array}{c}\text { observed } \\
\mathbf{Y} \\
(\mathrm{cm} .)\end{array}$ & $\begin{array}{c}\text { calc. } \\
Z_{3} \\
(\mathrm{~cm} .)\end{array}$ \\
\hline 8 & .09 & & 53 & $\ldots$ & .1 & 92 & & 0 \\
\hline 14 & 1.57 & 1.8 & 56 & & 2 & 98 & 1.1 & 3 \\
\hline 20 & 3.26 & 4.2 & 59 & & 4 & 101 & 1.3 & 6 \\
\hline 26 & 7.68 & 9.6 & 65 & $\ldots$. & 1.6 & 104 & 1.3 & .9 \\
\hline 32 & 22.6 & 20.7 & 71 & 11.1 & 4.8 & 110 & 1.0 & 1.2 \\
\hline 38 & 26.5 & 35.7 & 74 & 7.6 & 8.1 & 116 & 1.5 & 1.5 \\
\hline 44 & 44.0 & 44.1 & 78.8 & & 9.9 & 119 & 1.5 & 1.8 \\
\hline 50 & 38.9 & 35.7 & 80 & 10.1 & 9.6 & 122 & 1.1 & 1.5 \\
\hline 56 & 17.1 & 20.7 & 86 & 7.1 & 5.4 & 128 & 1.8 & 1.2 \\
\hline 62 & 12.5 & 9.6 & 92 & 1.4 & 1.8 & 134 & 1.1 & .9 \\
\hline 68 & 7.7 & 4.2 & 98 & 1.1 & 6 & 140 & .3 & .6 \\
\hline 71 & $\ldots$ & 2.7 & & & & 146 & .0 & .3 \\
\hline & & & & & & 152 & .1 & .0 \\
\hline
\end{tabular}
Values of Z Were Calculated From the Equations:

$$
\begin{aligned}
& \mathrm{Z}_{1}=.000177 y_{1}\left(380-y_{1}\right) \\
& \mathrm{z}_{2}=.0017 y_{2}\left(58-y_{2}\right) \\
& \mathrm{z}_{3}=.0024 y_{3}\left(20-y_{3}\right)
\end{aligned}
$$

The values obtained from these equations indicate the evelic nature of the growth process which governs the production of primary laterals. The curve (fig. 9) which represents the inean length of laterals in any group is symmetrical about the maximum value. The margins of the second group overlap those of the adjoining groups, and the calculated values of the overlapping portions must be added to approximate the observed values.

The satisfactory agreement between observed and calculated values seems to justify the conclusion that the length of each primary lateral was a function of its position in its group, and, consequently, of its position on the branch. The size of the group may depend to an even greater extent upon its position on the branch. The growth processes concerned with the production of laterals therefore bring about a definite spatial distribution of mass. 
The deereasing amplitude of the three curves suggests that the successive groups of laterals may represcnt damped oscillations of the growth process. The limits of the third group are too poorly defined, however, to afford satisfactory material for the study of this possibility.

\section{Secondary Laterals}

The secondary laterals are another distinet feature of the differentiation process in growth. Arising on the primary laterals, their existence is naturally conditioned to some extent by the faetors which govern the production of primary laterals and determine their length.

Figure 5 gives a graphical comparison of the frequeney distributions of primary and secondary laterals. The frequency polygon representing the distribution of the secondary laterals has much the same range as that representing the primary laterals, but is completely asymmetrical. The figures given in table 4 show that the standard deviation of the population as computed very nearly equals the mean. In sueh a case the mean fails to represent the population. It seems logical to conclude from these facts that the number of secondary laterals per branch is strongly affected by some factor which tends to keep the number at a minimum, for while the number per braneh ranged from 0 to 136 , more than two-fifths of the branches had less than 15 secondary katerals each.

$\Lambda$ classification of 2831 primary laterals with respect to the number of secondary laterals which each produced shows a still more asymmetrical distribution. The 483 secondary laterals on these branches were produeed on 17.06 per cent of the primary laterals, leaving 82.94 per cent which produced none. The majority of primary laterals which produced secondary laterals produced less than five each.

The production of secondary laterals with respect to the groups ot: primary laterals, elsewhere described, may also be noted. The average number of secondary laterals per braneh on the primary laterals of Group I was 33.61 \pm 2.53 ; on those of Group II, $1.86 \pm .26$; and on those of Group III, .19 \pm .08 . It is more than probable that the age factor was dominant in causing this distribution.

Viewed from either standpoint there is no evidence that the numbers of secondary laterals on these branches were governed by the laws of chance. On the contrary, there is evidence of some definite, active factor which tends to keep the buds on the primary laterals in a condition of dormancy until the end of the first year. The mumber of 
primary laterals on a branch does not depart widely from the values to be expected from the normal-curve type of variability, although it is modified by the location and position of the branch (see tables 5 and 6 ). The distribution of secondary laterals appears, however, to be widely different from that of the primary laterals.

The influence of the position of the branch upon the mean number of secondary laterals produced was found to be important, although subject to considerable variability. The figures given (table 14) show little difference in the numbers produced on branches which made an angle of less than 60 degrees from the perpendicular, but there was a much smaller number produced on branches which approached a horizontal position. The variability in the number of secondary laterals produced by all classes of branches is very great and gives support to a suggestion, for which I am indebted to Dr. H. B. Frost, viz., that the physiological processes were very sensitive and were readily turned in either direction by factors of an external or of an internal nature.

TABLE 14

INFLtence OF POSITION OF BRANCH UPON NuMBER OF SECONDARY

Laterals Produced

\begin{tabular}{|c|c|c|c|}
\hline Position of Branch & Mean & $\begin{array}{l}\text { Standard } \\
\text { deviation }\end{array}$ & $\begin{array}{l}\text { Coefficient of } \\
\text { variability }\end{array}$ \\
\hline $0^{\circ}-30^{\circ}$ from perpendicular & $54.67 \pm 8.72$ & $38.82 \pm 6.17$ & $71.01 \pm 16.02$ \\
\hline $30^{\circ}-60^{\circ}$ from perpendicular & $48.11 \pm 4.82$ & $37.10 \pm 3.40$ & $77.11 \pm 10.55$ \\
\hline $60^{\circ}-90^{\circ}$ from perpendicular & $21.19 \pm 2.26$ & $21.70 \pm 1.60$ & $102.41 \pm 13.10$ \\
\hline
\end{tabular}

In addition to the data showing the influence of the position of the branch, there are certain correlations which show something of the influence of internal factors upon the formation of secondary laterals. The cocfficient of correlation between the mean numbers of primary and secondary laterals per branch is

$$
r=.549 \pm .053
$$

This relationship might be expected on a priori grounds, since secondary laterals are produced only on primary laterals. It is logical to expect that an increase in the mean number of primary laterals per branch would, ceteris paribus, be followed by an increase in the number of secondary laterals (fig. 10). 
The production of secondary laterals is obviously dependent upon the ability of the branch to overcome the conditions which determine dormancy. This concept relates merely to the number of buds which grew into secondary laterals, not to the size of laterals produced. So far as problems of differentiation are conecrned release from dormancy is a matter of prime importance. Unless the potentiality of the bud can find kinetic expression, it counts for nothing in the further differentiation of the branch.

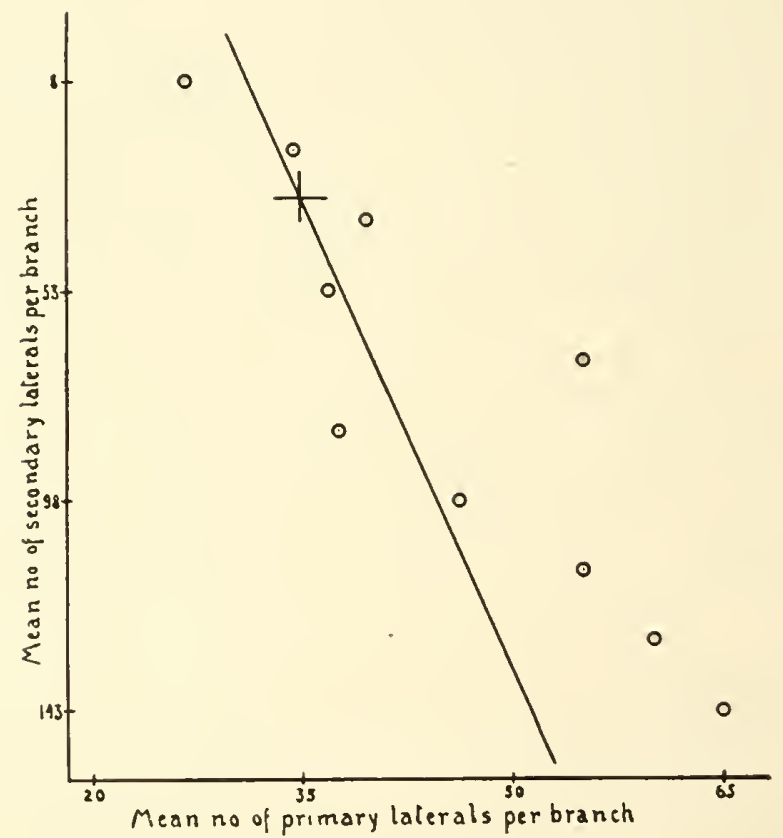

Fig. 10. Regression line of mean number of secondary laterals per branch on mean number of primary laterals.

The lengths of secondary laterals in Groups I and II have been studied with reference to their frequency and variability. So few secondary laterals were produced in Group III, that they were not included in the study. The frequency distributions are shown in figure 11 and exemplify a case of pronounced asymmetry. It will be remembered that the length distributions of primary laterals show a similar type of distribution. In both cases it is apparent that, among the factors which determine the length of a lateral, the chance variations of the enviromment play a small part. 
It is very interesting to note (table 9) that the mean length of secondary laterals in Groups I and II is the same in spite of the difference in age and position. The absence of any such relation in the primary laterals makes it doubtful whether there is any significance in this relationship, although it suggests that the forces involved in the growth of secondary laterals tend to come to a rather definite equilibrium.

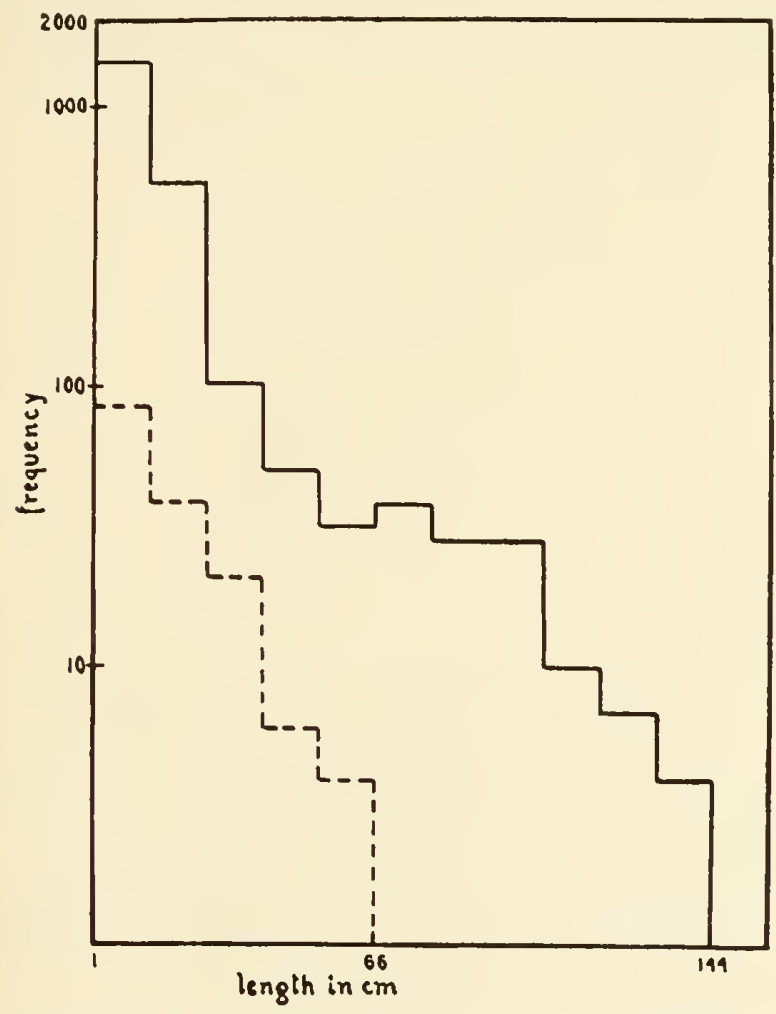

Fig 11. Frequency distributions for length of secondary laterals in Groups I and II, plotted on logarithmic seales. Group I, —-, Group II, - - -

The relation of the mean number of secondary laterals on a branch to their mean length expressed as a coefficient of correlation is

$$
r=.148 \pm .078 \text {. }
$$

This coefficient is not large and, moreover, is only twice its probable error; consequently it fails to denote any significant correlation between the two variables. If the amount of unformed matcrials in the branch were more or less constant, we should then expect to find a definite negative correlation between these two variables, because 
where few laterals were produced they would have more material to draw upon and consequently attain a greater size. The lack of any strong correlation shows that the size of the laterals is independent of any such factor. Indeed, if any weight be laid upon the coefficient, it must be interpreted in quite the opposite direction, i.e., the more laterals produced, the greater will be their average length. Doubtless this tendency would be more pronounced were it not for the fact that the manufacture of sufficient photosynthates is limited by the crowding and consequent shading of laterals during the growing season.

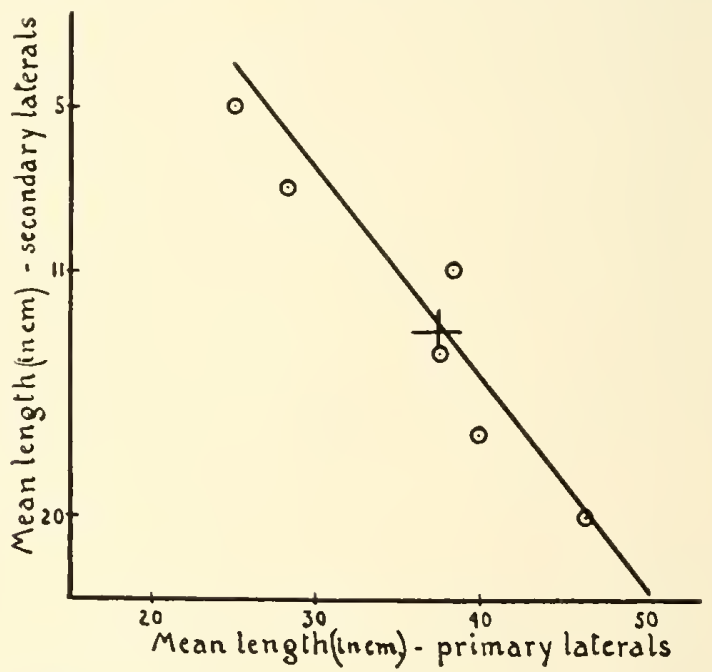

Fig. 12. Regression line of mean length (per branch) of secondary laterals on mean length of primary laterals.

Another important correlation is that which exists between the mean length of primary and secondary laterals of each branch. The cocfficient expressing this correlation is

$$
r=.467 \pm .062 \text {. }
$$

This expresses a strong positive correlation between the two variables and may be taken as evidence that the factors which determine the size of primary laterals on a branch operate in the same way on the secondary laterals. The validity of the correlation is shown by the linearity of regression (fig. 12).

This coefficient of correlation expresses concisely a relationship which was suggested by the rough parallelism of the polygons (fig. 5) showing the frequency distributions of the numbers of primary and secondary laterals per branch. Both distributions have the greatest frequencies in the region of the smaller numbers of laterals per branch. 


\section{Buossoms}

The formation of blossoms is an important stage in growth and differentiation. The blossom bud is a highly energized center on the vegetative organs toward which flow some of the most important synthetic materials from other parts of the tree. So far as the perpetuation of the species is concerned, the formation of a sufficient number of viable fruit buds is one of the factors of suecess in the struggle for existence. The horticulturist has an obvious interest in the factors which govern the formation of a maxinum number of buds on fruit trees.

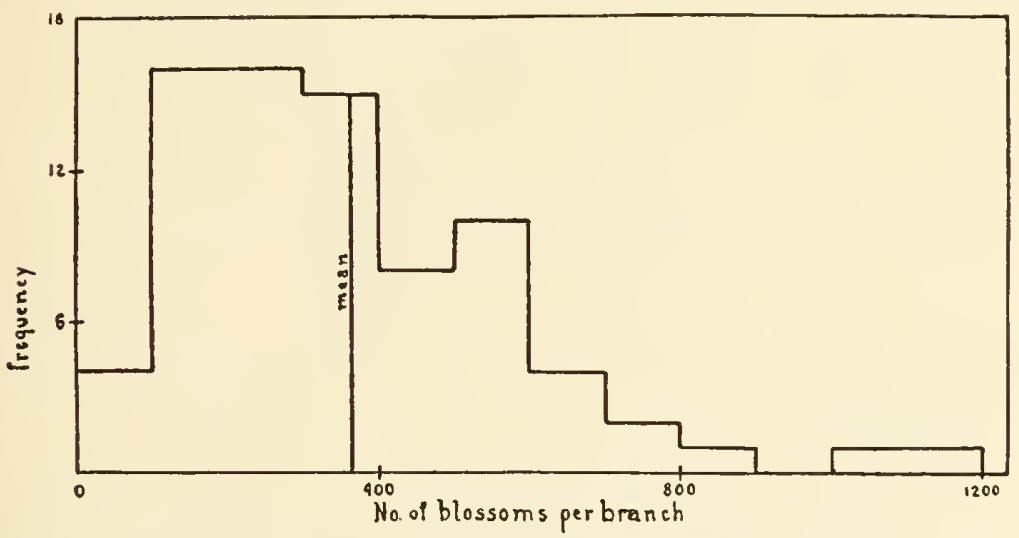

Fig. 13. Frequency distribution for number of blossoms on apricot branches.

The problem of fruit-bud formation on the apricot tree is broader than the aspects dealt with here, because most of the fruit buds are produced on laterals which appear after the branch is one year old. It is well known that such conditions are not favorable for the production of a maximum number of blossom buds. The problem here attacked is the production of fruit buds on branches which are making rapid vegetative growth in the first season.

The salient features of the number and variability of blossoms are shown in table 15 and in figure 13. The number of blossoms per branch ranged from 50 to 1200 with the mean at $360.26 \pm 16.62$. The great variability in the number of blossoms per branch is shown by the frequency polygon and by the coefficient of variability of $60.39 \pm 4.28$. This frequency polygon bears a certain resemblance to those representing the distribution of laterals, since it also has the highest frequencies in the region of a minimum number of blossoms per branch. 


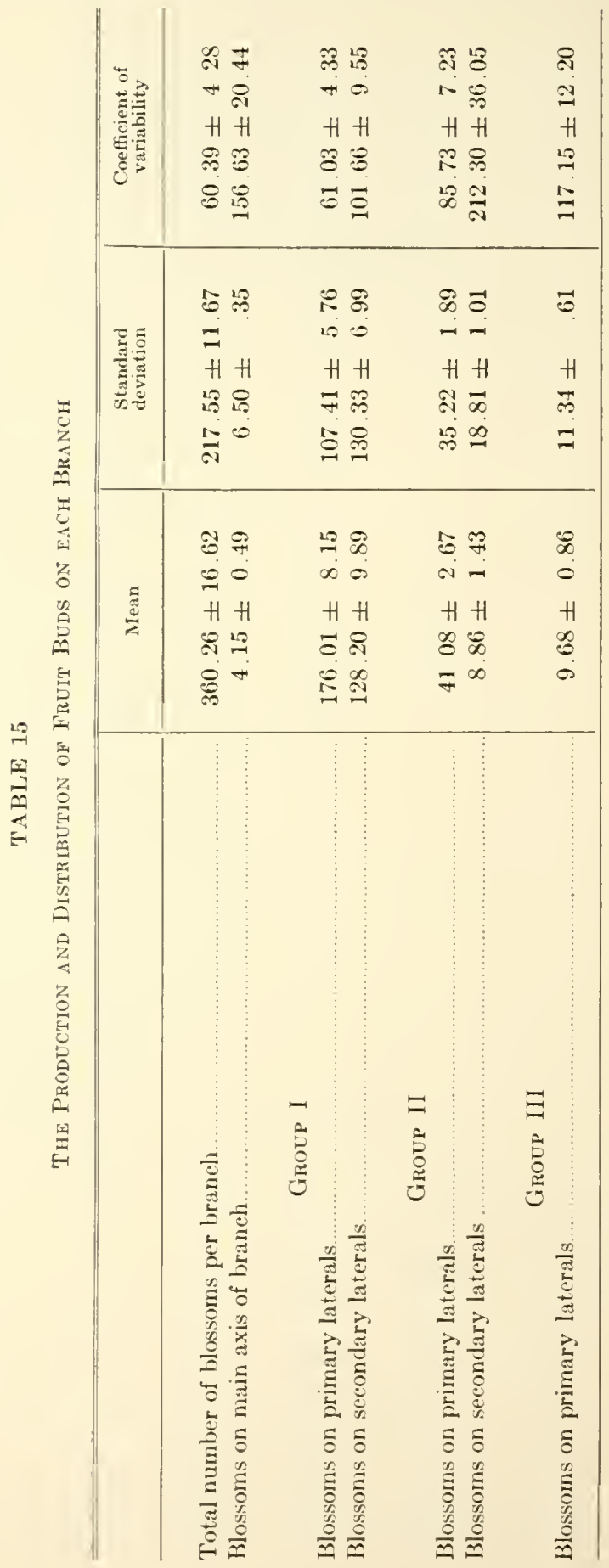


The main axis of the branch bore very few blossoms, the majority of them being produced upon primary laterals.

The primary laterals of Group I produced the greater part of the blossoms and the variability of the mean number per lateral is less than in the more distally located groups. The variability of the means in all these groups is relatively enormous.

The decrease in the number and the increase in the variability of the numbers of blossoms in the distal regions of the branches may be due to a number of causes, anong which we must recognize growth. While the distal region was growing, the physiological functions of that part were opposed to the formation of the energy centers which form blossom rudiments. In the proximal region, growth in mass had largely ceased so long before the end of the season that the development of blossom rudiments was not opposed by other functions. The effect of the migration and localization of materials in the branch is a biochemical question which will not be discussed here. Hooker, 3 has made a significant beginning in the study of these factors and Barker and Lees ${ }^{1}$ have approached the problem by a somewhat different route.

Since blossoms were produced mainly mpon laterals, any factor which increases the production of laterals may also increase the production of blossoms. The coefficient of correlation between the number of blossoms per branch and the ratio of primary laterals to total number of nodes per branch is

$$
r=.386 \pm .065
$$

This coefficient might be expected to measure the effect of the factors which overeome dormancy on the production of blossoms. One may assume that substances moving into the branch go either to the production of laterals or to the formation of flower rudiments. If, from any cause, the number of primary laterals were relatively small, the material might be used in forming flower rudiments. If the number of laterals were relatively large, they might so compete with flower-bud formation as to lessen the number of flowers formed; but this correlation coefficient speaks against the validity of such an assumption. The coefficient is positive and indicates that factors which cause the formation of numerous laterals also tend to form a larger number of flower buds. It is not improbable that the formation of primary laterals, through their ability to increase the amount of photosynthates, increases the formation of flower buds. Again, it is possible that the formation of the two kinds of units (laterals and flower buds) is an expression of the same tendency to differentiation. 
The next step in this study was designed to answer the question, Is there any relation between the length of a lateral and the number of blossoms it bears? There is an opinion eurrent that short laterals are the most precocious in fruiting habits. This opinion, however, may be due to the fact that the blossoms on them must of necessity be elose together and are therefore more conspicuous. A more accurate idea of the relationship may be obtained by ascertaining the correlation coefficient between the number of blossoms and the number of nodes of the laterals.

Correlation coefficients were determined for 972 primary laterals in Group I, since this is the largest and most representative group of laterals. If

$a^{\prime}=$ number of blossoms on primary laterals

$b^{\prime}=$ number of nodes on primary laterals

$c^{\prime}=$ length of primary laterals

the coefficients of correlation are

$$
\begin{aligned}
& r_{a^{\prime} b^{\prime}}=.089 \pm .020 \\
& r_{a^{\prime} c^{\prime}}=.077 \pm .020 \\
& r_{b^{\prime} c^{\prime}}=.969 \pm .014
\end{aligned}
$$

The coeffieient representing the correlation between the numbers of blossoms and nodes is small, and of very doubtful significance; the same holds true of the correlation between number of blossoms and length of lateral. The third coefficient shows, as one might predict, a very high correlation between the length of a lateral and the number of nodes it bears.

On the face of these coefficients of gross correlation, we should conclude that there is practically no association between the number of nodes and the number of blossoms a lateral may bear. The problem is a bit complicated by the fact that the laterals are of different lengths, but this factor may be eliminated by making the partial correlation between the numbers of buds and nodes.

$$
a^{\prime} b^{\prime} r_{c^{\prime}}=.059 \pm .021
$$

This coefficient shows very plainly that there is no correlation between the number of blossoms and the number of nodes on the laterals. That is to say, a short lateral may have as many blossoms as a long lateral.

The character of the correlation coefficient may be marle a bit plainer by referring to the curve of means of $y_{x}$ in figure 14 , which slows the mean number of blossoms produced upon the laterals 
possessing varying numbers of nodes. The curve of the means of blossoms for primary laterals shows that we are not here dealing with a case of linear regression and that the coefficient of gross correlation is therefore somewhat lacking in reliability. It is interesting to note that the greatest nean number of blossoms occurred on laterals bearing from 30 to 60 nodes.

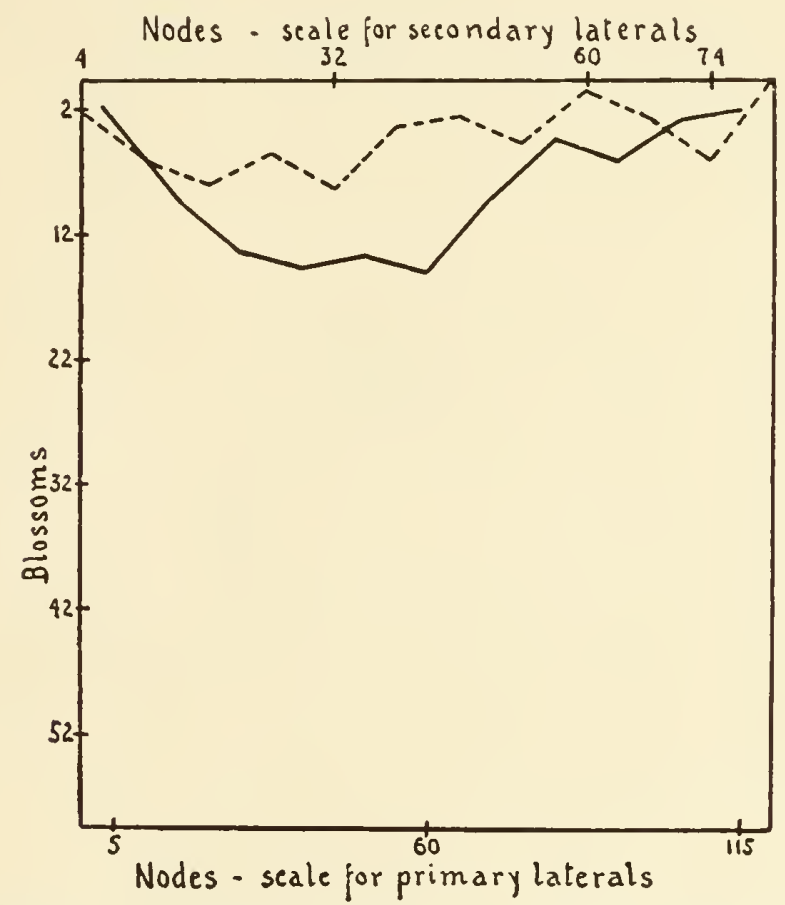

Fig. 14. Relation of the number of blossoms to the number of nodes. Curves of the means of $y_{x}$. Primary laterals, _- ; secondary laterals, - - - .

A better idea of the relations between the two characters may be grasped from the representation of the blossom-node distribution as shown in figure 15. This blossom-node surface shows that there are two kinds of primary laterals on apricot branches. The larger class has a tendeney toward a linear regression of blossoms on nodes, i.e., the more nodes the more blossoms. It is true that the ellipses slowing the distribution values are imperfect, but that is because the frequency distributions of these values are so asymmetrical (fig. 13). The smaller class of laterals is indicated by the partial ellipses in the upper right portion of the blossom-11ode surface. These laterals were characterized by many nodes and few blossoms. This blossom-node surface there- 
fore shows clearly that the apricot branches possessed a large number of fruiting laterals and a smaller number of vegetative laterals. It also shows why the curve of means of $y_{x}$ has an upward trend in the nodal classes of high values.

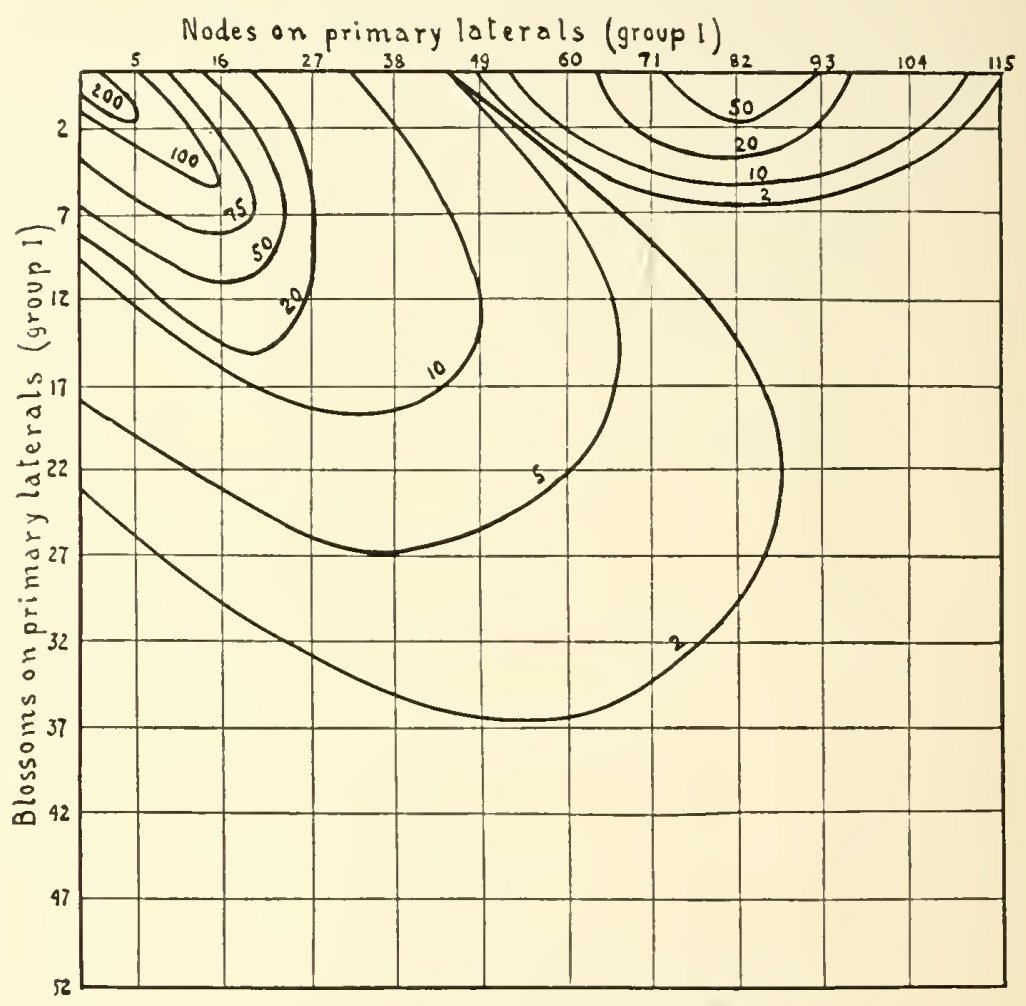

Fig. 15. Blossom-node surface for primary laterals.

The blossoms on the secondary laterals borne on primary laterals of Group I were also studied in somewhat the same manner. The frequeney distributions of blossoms and nodes on the secondary laterals were of the same asymmetrical types as on the primary laterals and the coefficients of gross correlation were similar.

The following notation was used:

$$
\begin{aligned}
& a^{\prime \prime}=\text { number of blossoms on secondary laterals } \\
& b^{\prime \prime}=\text { number of nodes on secondary lateral } \\
& c^{\prime \prime}=\text { length of secondary lateral }
\end{aligned}
$$

The coefficients of eorrelation as determined for a population of $\mathbf{1 3 7 0}$ secondary laterals were

$$
\begin{aligned}
& r_{a^{\prime \prime} b^{\prime \prime}}=.118 \pm .018 \\
& r_{a^{\prime \prime} c^{\prime \prime}}=.122 \pm .018 \\
& r_{b^{\prime \prime} c^{\prime \prime}}=.971 \pm .001
\end{aligned}
$$


The first two coefficients are somewhat more reliable than the corresponding determinations on primary laterals, but they cannot be regarded as indicating any strong degree of association between the characters concerned. Indeed, it is evident from otler relations that the number of blossoms a secondary lateral bore was quite independent of the number of nodes or of its length. The coefficient of partial correlation is

$$
a^{\prime \prime} b^{\prime \prime} r_{c^{\prime \prime}}=-.002 \pm .018
$$

In view of the fact that the value of this coefficient is practically zero, it is evident that if all the secondary laterals were of equal length, there would be no correlation between the numbers of blossoms and nodes upon them.

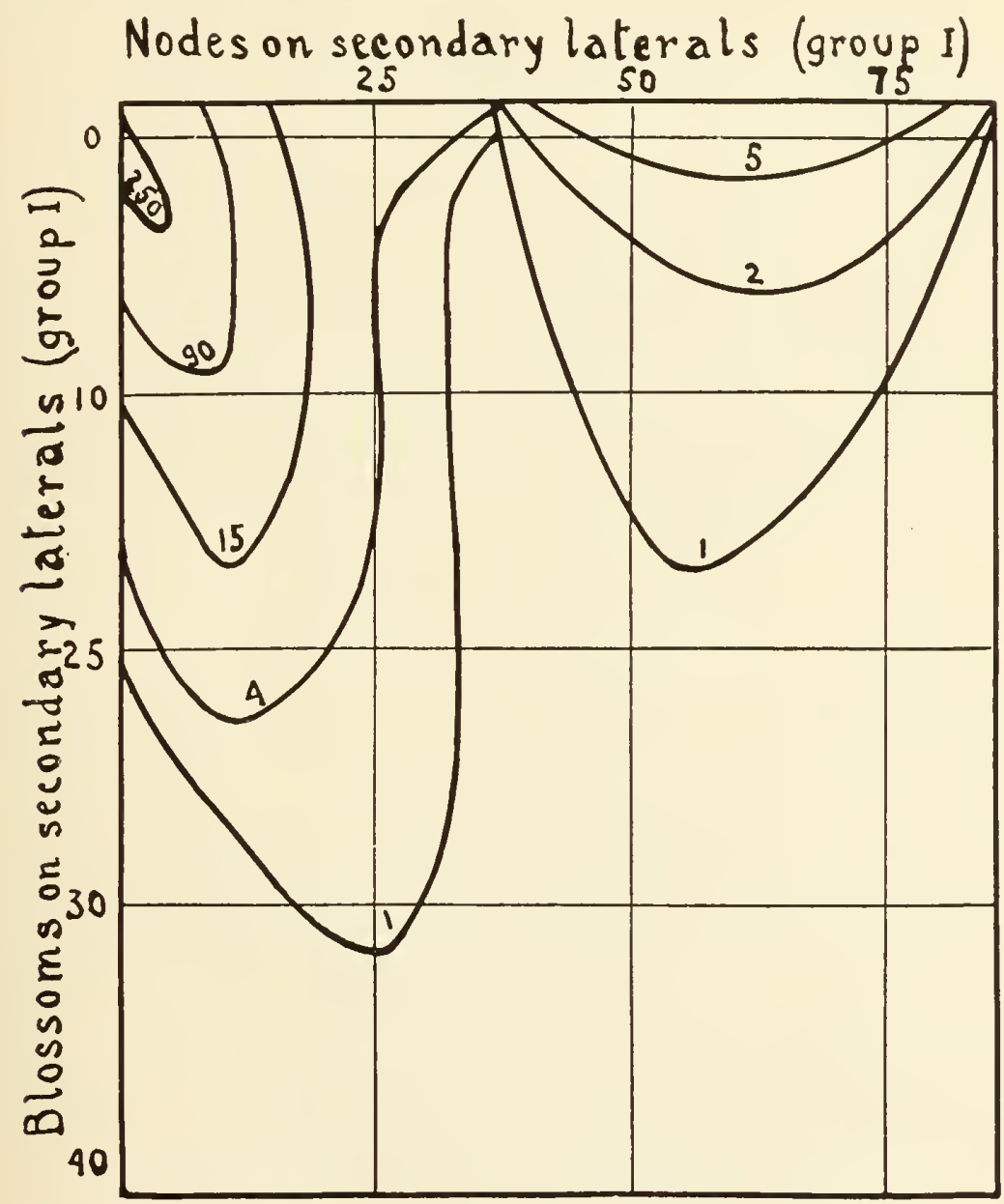

Fig. 16. Blossom-node surface for secondary laterals. 
The curve of the means of $y_{x}$ (fig. 14) shows that the mean numbers of blossoms on elasses of laterals with varying numbers of nodes were not signifieantly different, in faet, they were remarkably eonstant. The aetnal range for values of $y_{x}$ was 0 to 8.16. It is evident from these values that we are not dealing with a ease of linear regression between these two charaeters.

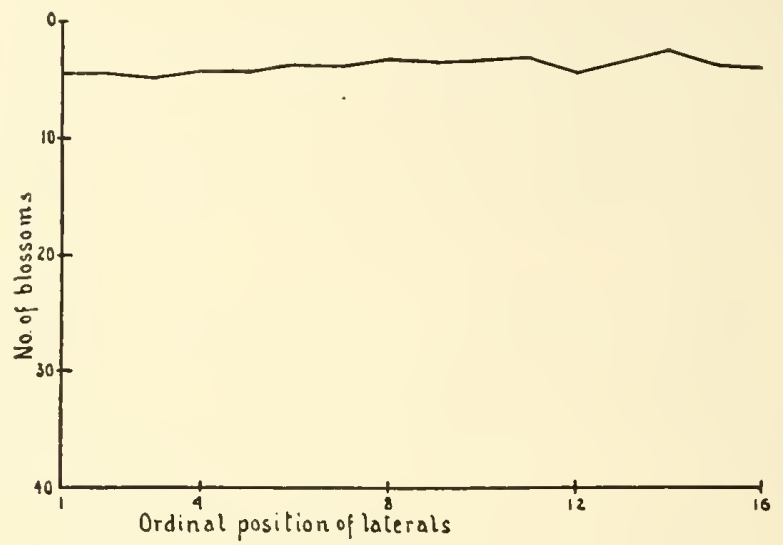

Fig. 17. Relation of the number of blossoms to the position of the secondary lateral on which they were borne. Curve of the means of $y_{x}$.

The aetual distribution of blossoms on the secondary laterals is well shown by figure 16. Here, again, we see that there are two rather distinet elasses of laterals, one of which bore many more blossoms in proportion to the number of nodes than the other. The first class ineludes laterals having less than 40 nodes and the partial ellipses representing their distribution have axes sloping rather steeply downward. The other group which contains long laterals appears to be distinetly vegetative in eharacter; at least, it bore relatively few blossoms in proportion to its number of nodes.

One further aspeet of the distribution of blossoms was investigated, viz., the correlation between the position of a secondary lateral and the number of blossoms it bore. It is interesting to know whether the lower laterals in a group produeed more or less blossoms than the upper laterals. The reeords of 2011 secondary laterals on primary laterals of Group I were used in making the correlation table. They were counted in sueeession, the lateral nearest the base of the primary lateral on whieh they were borne being designated as number one. The eoeffieient of correlation between these variables was

$$
r=-.109 \pm .022 \text {. }
$$


It indicates only a small degree of negative correlation and may be intcrpreted to mean that the lower laterals were only slightly if at all superior to others in the production of blossoms.

The remarkable uniformity in the ncan number of blossoms on laterals is shown by the means of $y_{x}$ (fig. 17). From this we may infer that it was neither the number of nodes on a lateral nor the ordinal position of the lateral which determined the number of blossoms it bore, but some other, as yet, unknown factor.

\section{GENERAL SURVEY OF CORRELATED VARIABILITY IN TIE APRICOT BRANCH}

T'he method of presenting correlations employed in figure 18 gives a comprehensive idea of the relations existing between the variables whose correlation has been discussed on widely separated pages. The manner in which the coefficients are shown on the lines which connect the names of the characters whose correlation was determined calls for little additional discussion.

The length of the branch was employed as the central character from which others radiate, since the length of that nember seems to be an excellent index of growth. The inajority of the coefficients are large enough in comparison with their probable errors to be significant. In the cases where one variable is very dependent upon another, e.g., where the number of nodes depends almost entirely upon the length of the laterals, the coefficient of correlation between the two variables is very high.

\section{SUMMARY}

1. The pattern of the organism is the result of a process of growth and differentiation which is largely an expression of inherent factors. Growth and differentiation lead to a quantitative distribution of matter in space that makes it necessary to regard the position and size of members of the branches as the expression of an inherent tendency which varies within limits under the influence of the ever-varying environment.

2. The main axis of the apricot branch shows distinct cycles of growth during the first season, each of which may be expressed by a logarithmic equation similar to that of autocatalysis. The maximum rate of growth was reached in the fifth and sixth weeks. 
3. The branches in the population studied were less variable in length than in any other charactcr. Their frequency polygon for length is fairly symmetrical with respect to its mean and does not depart widely from the type of polygon which represents a chance distribution of characters in biological material. The mean length of all laterals was more than seven times that of the branches on which they were borne. The degree of association between number of laterals per branch and the length of the branch was not high; but it was high between the length of branch and length of laterals it bore. The location of the branches and their angle with the perpendicular had certain effects upon their growth and differentiation. Branches on the north side of the tree produced the maximum number of primary laterals and blossoms. Branches which made an angle of 60 to 90 degrees with the perpendicular had ferver laterals and blossoms than those which were more nearly upright, although the ratio of blossoms to unit length of lateral was greater on the horizontal branches.

4. The distribution of laterals and blossoms showed wide divergence from the normal frequency distribution of variables. Groups containing the smaller numbers of laterals and blossoms per branch had by far the greatest frequencies. The types of distribution here studied appear to depend, not upon the chance factors of the environment, but upon fundamental internal conditions of differentiation. These internal conditions are obviously grounded in the basic growth tendencies of the cells, that is to say, in their genetic constitution, and are especially conditioned by certain inescapable spatial limitations. A striking result of these conditions is that relatively large growth occurs in a few buds and shoots, while relatively slight growth (or none) oceurs in many buds and shoots. We find, therefore, a general tendency toward distributions showing positive skewness, with or without zero classes. The close approach in this study to a Gaussian distribution for 'branch' length is doubtless due to the method of initial sampling; only shoots in favorable locations were selected for study, and the feebler majority was thus eliminated.

5. Most of the nodes remained dormant through the first season. The ratio of nodes whicl produced laterals is such that it indicates a cyclic distribution of the forces which break the dormancy of lateral buds. 


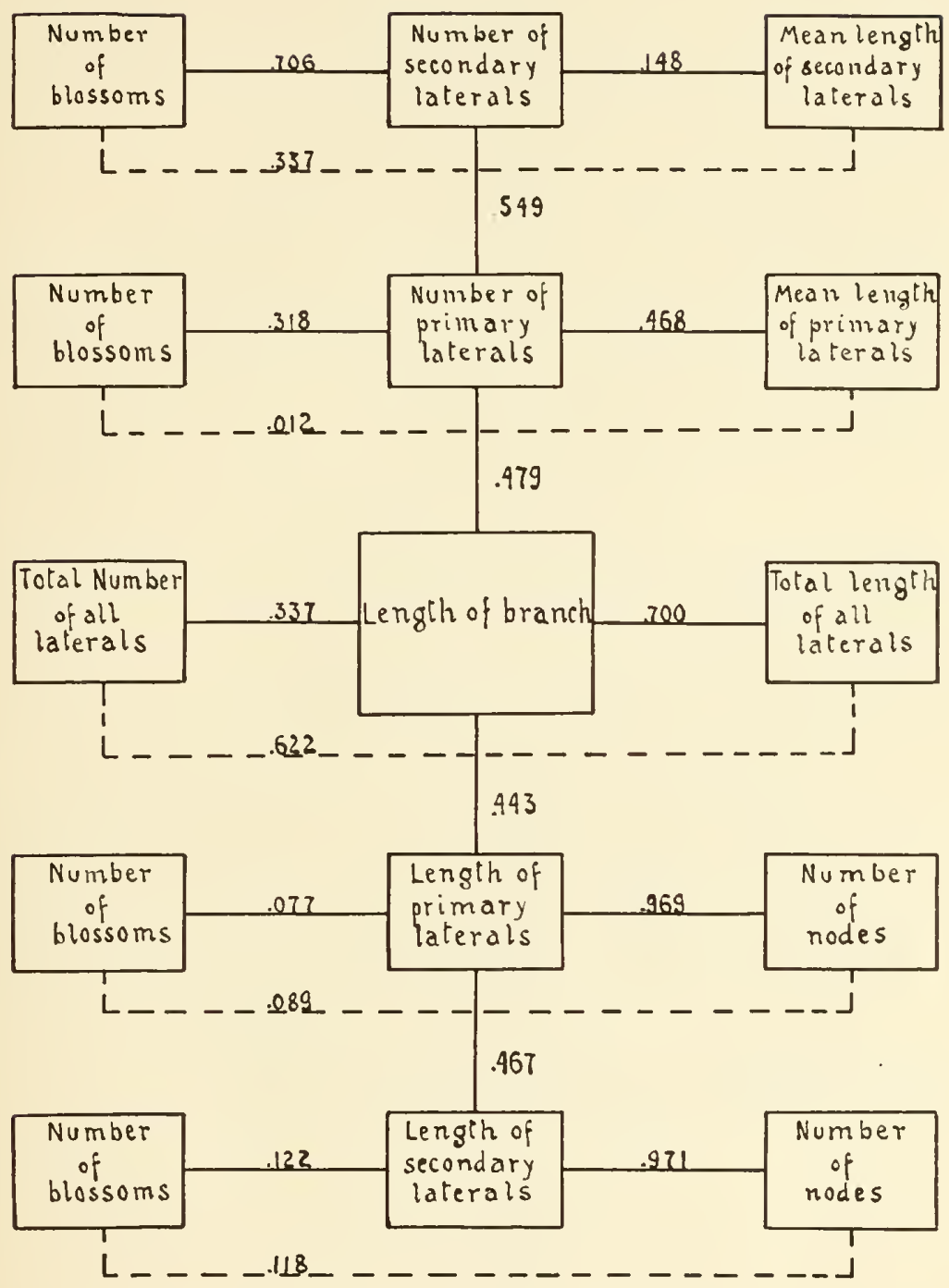

Fig. 18. Diagram representing correlations between certain characters. 
6. The eonfiguration of primary laterals on the braneh afforded suitable material for the study of the statics of eyclie growth and gave satisfactory evidenee of a definite distribution of matter in space. The production of material for the formation of laterals appears to follow the same mathematieal relations as does the growth of the braneh. A method is deseribed by which it was possible to eompute the length of a lateral situated at a given node.

7. The general form of frequency distribution of the numbers and lengths of secondary laterals does not appear to be eonditioned to any great extent by the faetors located in the environment. The mean number of seeondary laterals per braneh showed rather a high positive correlation with the mean number of primary laterals. The eorrelation between the mean number of seeondary laterals and their mean length indicated that the size of the laterals is not dependent upon the faetors whieh determine their numbers. The mean lengths of primary and secondary laterals on a braneh showed a eorrelation which indicated that the factors whieh operated to determine the length of one order of laterals acted similarly on the other elass.

8. The main axis of the branch produced very few blossoms in the following season; the primary laterals bore the majority of those produced. The mean number of blossoms per lateral tended to be rather constant regardless of the length of the lateral, and indicates that random factors of the enviromment were less important than internal factors of differentiation in determining distribution. The blossomnode surface gave good evidence of the oceurrence of two elasses of laterals on apricot branches; the larger elass showed a tendency toward a linear regression of blossoms on nodes, while the smaller class was charaeterized by the possession of many nodes and few blossoms, and showed no definite tendeney toward linear regression. 


\section{LITERATURE CITED}

1 BARKER, B. T. P., and LEES, A. H.

1916, 1919. Factors governing fruit-bud formation. Agr. and Hort. Res. Sta., Bristol, Ann. Rept. 1916, pp. 46-64; 1919, pp. 85-98.

2 HOOKER, H. D.

1921. Localization of the factors determining fruit-bud formation. Missouri Agr. Exp. Sta., Res. Bull. 47.

3 HCOKER, H. D.

1922. Certain responses of apple trees to nitrogen applications of different kinds and at different seasons. Ibid., 50.

4 MASON, T. G.

1922. Growth and correlation in Sea Island cotton. West Indian Bull., vol. 19, pp. 214-238.

5 Priestley, J. H., and Pearsall, W. H.

1922. Growth studies. II. An interpretation of some growth-curves. Ann. Bot., vol. 36 , pp. 239-249.

6 REED, H. S.

1920. The dynamies of fluctuating growth rate. Proe. Nat. Acad. Sei., vol. $6, \mathrm{pp} .397-410$.

7 REED, H. S.

1920. Slow and rapid growth. Am. Jour. Bot., vol. 7, pp. 327-332.

8 REED, H. S.

1921. Growth and sap concentration. Jour. Agr. Res., vol. 21, pp. 81-98.

9 REED, H. S.

1921. Correlation and growth in the branches of young pear trees. Jour. Agr. Res. vol. 21, pp. 849-876.

10 ReEd, H. S., and Halma, F. F.

1919. On the existence of a growth-inhibiting substance in the Chinese lemon. Univ. Calif. Publ. Agr. Sci., vol. 4, pp. 90-112.

11 Reed, H. S., and Halma, F. F.

1919. The evidence for a growth-inhibiting substance in the pear tree. Plant World, vol, 22, pp. 239-247.

12 SPENCER, H.

1893. Principles of biology, vol. 2, p. 215.

13 Ropertson, T. B.

1915. Tables for the computation of curves of autocatalysis, with especial reference to curves of growth. Univ. Calif. Publ. Physiol., vol. 4, pp. 211-228.

14 Thом PSON, R.

1835. A report upon the varieties of apricot eultivated in the garden of the horticultural society. Read Feb. 15, 1831. Trans. Roy. Hort. Soc., London, ser. 2, vol. 1, p. 63. 



\section{UNIVERSITY OF CAIIFORNIA PUBLICATIONS-(Continued)}

4. Further Studies on the Distribution and Activities of Certain Groups of Bacteria in California Soil Columns by Charles B. Lipman. Pp. 113-120. April, 1919

6. Variability in Soils and Its Significance to Past and Future Soil Investigations. II. Variations in Nitrogen and Carbon in Field Solls and Their Relation to the Accuracy of Field Trtals, by D. D. Waynick and I. T. Sharp. Pp. 121-139, 1 text figure. May, 1919

6. The Effect of Several Types of Irrigation Water on the PH Value and Freezing Point Depression of Various Types of Soils, by D. R. Hoagland and A. W. Christie. Pp. 141-157. November, 1919

7. A New and Simplified Method for the Statistical Interpretation of Blometrical Data, by George A. Iinhart. Pp. 159-181, 12 text figures. September, 1920

8. The Temperature Relations of Growth in Certain Parasitic Fungh, by Howard S. Fawcett. Pp. 183-232, 11 text figures. March, 1921

9. The Alnement Chart Method of Preparing Tree Volume Tables, by Donald Bruce. Pp. 233-243. December, 1921

10. Equilibrium Studies with Certain Acids and Minerals and their Probable Relation to the Decomposition of Minerals by Bacteria, by Douglas Wright, Jr. Pp. 245-337, 35 text figures. March, 1922

11. Studies on a Drained Marsh Soil Unproductive for Peas, by Paul S. Burgess. Pp. 339-396, 21 text figures. June, 1922

12. The Effect of Reaction on the Fixation of Nitrogen by Azotobacter, by Harlan W. Johnson and Charles B. Lipman. Pp. 397-405, 3 text figures. December, 1922

13. The Toxicity of Copper Sulfate to the Spores of Tilletia tritici (Bjerk.) Winter, by Fred N. Briggs. Pp. 407-412, 1 figure in text. November, 1923

14. Influence of Reaction on Inter-Relations Between the Plant and its Culture Medinm, by J. J. Theron. Pp. 413-444, 12 figures in text. January, 1924

Vol. 5. 1. Growth and Differentiation in Apricot Trees, by H. S. Reed. Pp. 1-55, 18 figures in text. September, 1924

AGRICULTURE.-The Publications of the Agricultural Experiment station consist of Bulletins and Biennial Reports edited by Professor Thomas Forsyth Hnnt, Director of the Station. These are sent gratis to citizens of the State of California. For detailed information regarding them address the Agricultural Experiment Station, Berkeley, California.

BOTANY.-W. A. Setchell and R. C. Holman, Editors. Volumes I-IV $\$ 3.50$ per volume; volume $V$ and following $\$ 5.00$ per volume. Volumes I (pp. 418), II (pp. 360), III ( pleted. Volumes VII, VIII, $\mathrm{X}, \mathrm{XI}$, and XII in progress.

Vol 7. 1. Notes on the Callfornia Species of Trillium I. A Report on the General Results of Field and Garden Studies, 1911-1916, by Thomas Harper Goodand Robert Percy Brandt. Pp. 1-24, plates 1-4. October, 1916

2. (The same.) The Nature and Occurrence of Undeveloped Flowers, by Thomas Harper Goodspeed and Robert Percy Brandt. Pp. 25-38, plates 5-6. Octo ber, 1916

8. (The same.) Seasonal Changes in Trillium Species with Special Reference to the Reproductive Tissues, by Robert Percy Brandt. Pp. 39-68, plates 7-10. December, 1916

4. (The same.) Teratological Variations of Trillium sessile var. giganteum, by Thomas Harper Goodspeed. Pp. 69-100, plates 11-17. January, 1917........

5. A Preliminary Iist of the Uredinales of California, by Walter C. Blasdale. Pp. 101-157. . August, 1919

6. A Rubber Plant Survey of Western North America. I. Chrysothamnus nauseosus and Its Varieties, by Harvey Monroe Hall and Thomas Harper Goodspeed. Pp. 159-181.

7. (The same.) II, Chrysil, a New Rubber from Chrysothamnus nauseosus, by Harvey Monroe Hall. Pp. 183-264, plates 18-20, 6 figures in text.

8. (The same.) III. The Occurrence of Rubler in Certain West American Shrubs, by Harvey Monroe Hall and Thomas Harper Goodspeed. Pp. 265-278, 2 figures in text.

Nos. 6, 7, and 8 in one cover. November, 1919

9. Phycological Contributions. I, by William Albert Setchell and Nathaniel Lyon Gardner. Pp. 279-324, plates 21-31. July, 1920 
UNIVERSITY OF CAIIFORNIA PUBLICATIONS-(Continued)

10. Plantae Mexicanae Purpusianae. $\mathbf{X}$, by Townshend Stith Brandegee. Docember, 1920

11. Phycological Contributions, II to VI. II, New Species of Myrlonema; III, New Species of Composonema; IV, New Specles of Hecatonema; $\nabla$, New Species of Pylalella and Streblonema; VI, New Specles of Ecta carpus, by William Albert Setchell and Nathaniel Lyon Gardner, Pp. 333-426, plates 32-39. May, 1922.

12. Notes on Pacific Coast Algae. II, On the Californian "Dolesseria Quercifolla," by Carl Skottsberg. Pp. 427-436, plate 50. June, 1922

13. Undescribed Plants mostly from Baja California, by Ivan Murray Johnston. Pp. 437-446. August, 1922

14. The Morphology, Development, and Economic Aspects of Schizophyllum commune Fries, by Frederick Monroo Essig. Pp. 447-498, plates 51-61 August, 1922

Vol. 8. 1. The IMarine Algae of the Pacific Coast of North America. Part I. Myxophyceae, by William Albert Setchell and Nathaniel Iyon Gardner. Pp. 1-138, plates 1-8. November, 1919

2. (The same.) Part II. Chlorophyceae, by Wllliam Albert Setchell and Nathaniel Lyon Gardner. Pp. 139-374, plates 9-33. July, 1920

Vol 9. A Report upon the Boreal Flora of the Sierra Nevada of California, by Frank Jason Smiley. 423 pages, 7 plates. October, 1921

Vol. 10. 1. The Genus Fucus on the Pacific Coast of North America, by Nathantel Lyon Gardner. Pp. 1-180, pls. 1-60. April, 1922

2. Plantae Mexicanae Purpusianae, XI, by Townshend Stith Brandegee. Pp. 181-188. November, 1922

3. A Revision of the Californian Species of Lotus, by Alice M. Ottley. Pp. 189-305, plates 61-82, 10 maps. August, 1923

4. Notes on a Collection of Now Zealand Hepaticae, by William Henry Pear. son. Pp. 307-370, plates 83-103.

5. More New Zealand Hepaticae, by William Henry Pearson. Pp. 373-392, plates 104-109.

Nos. 4 and 5 in one cover. June, 1923

6. Parasitic Florideae II, by William Albert Setchell. Pp. 393-396.

7. A Revision of the West North American Species of Callophyllis, by William Albert Setchell. Pp. 397-401.

Nos. 6 and 7 in one cover. May, 1923

Vol. 11. 1. Interspecific Hybridization in Nicotiana. On the Results of Backcrossing the $\mathbf{F}_{1}$ Sylvestris-Tabacum Hybrids to Sylvestris, by Thomas Harper Goodspeed and Roy Elwood Clausen. Pp. 1-30, 12 figures in text. Augrust, 1922

Vol. 12. 1. Ischenes a W. A. Setchell et H. F. Parks in Insula Tahiti a 1922 Collecti, scripsit Edv. A. Vainio. Pp. 1-16, January, 1924

Report upon a Collection of Ferns from Tahiti, by William A Maxon. Pp. 17-44, plates 1-6. May, 1924 .

3. Tahitian Mosses, Collected by W. A. Setchell and H. E. Parks, Determined by $\nabla$. F. Brotherus. Py. 45-48. September, 1924 